\title{
THE VANISHING PUBLIC DOMAIN: ANTIBIOTIC RESISTANCE, PHARMACEUTICAL INNOVATION AND INTELLECTUAL PROPERTY LAW
}

\author{
Kevin Outterson ${ }^{*}$
}

\section{INTRODUCTION}

Penicillin and other antibiotics were the original wonder drugs and laid the foundation of the modern pharmaceutical industry. Human health significantly improved with the introduction of antibiotics. ${ }^{1}$ By 1967, the U.S. Surgeon General declared victory over infectious diseases in the United States. ${ }^{2}$ But pride goes before a fall. ${ }^{3}$ The evolutionary pressure of antibiotic use selects for resistant strains. Effective drugs should be used. But when they are used, no matter how carefully, evolutionary pressure for resistance is

* Associate Professor of Law, West Virginia University. Kevin.Outterson@mail.wvu.edu. I am grateful to IMS Health for the generous provision of a time series of antibiotic sales data which has been utilized in this study. Portions of this Article were prepared for the World Health Organization Commission on Intellectual Property Rights, Innovation and Public Health. Portions of Section II.C were presented as testimony in hearings before the U.S. Senate Committee on Health, Education, Labor and Pensions on February 17, 2005. The Article was presented at the Second Annual Intellectual Property and Communications Law and Policy Roundtable at Michigan State University in February 2005 and at the 29th Annual Health Law Teachers' Conference at the Baylor College of Medicine and the University of Houston Law Center on June 2, 2005. Additional comments on this paper were received from James Boyle, John Erickson, Dr. Alan Schechter, Samantha Chaifetz, Sanjay Basu, Matthew Rimmer, Aiden Hollis, Olufunmilayo B. Arewa, Dr. Joel Lexchin, Andrew Farlow and Caprice Roberts. I am also grateful that Philip Allott encouraged us to think from the perspective of all-humanity. David Davis provided valuable research assistance. Finally, this article is indebted to the work of Eric Kades, although Idisagree with him on many points.

1. Stuart B. Levy, The Antibiotic Paradox: How the Misuse of Antibiotics Destroys Their Curative Powers (2d ed. 2002). Life expectancy at birth in the United States has risen by about 13 years and 7 months since antibiotics became widely available. See Elizabeth Arias, NAt'L Ctr. fOr Health Statistics, 53 National Vital Statistics Repor ts No. 6, United States Life Tables, 2002, at 29 tbl. 11 (2004) (reporting life expectancy values, which allows for the calculation of the aforementioned increase via using the difference in life expectancy values for 1939-41 versus 2002). The Infectious Diseases Society of America attributes much of that improvement to antibiotics, although the data is not conclusive. Infectious Diseases Soc'y of Am., Bad Bugs, No Drugs: As Antibiotic Discovery Stagna tes ... A Public Health Crisis Brews 9 (July 2004) [hereinafter Bad Bugs].

2. See Ruth L. Berkelman \& James M. Hughes, The Conquest of Infectious Diseases: Who Are We Kidding?, 119 Annals of Internal Med. 426 (1993).

3. The full quote is: "Pride goes before destruction, and a haughty spirit before a fall." Proverbs 16:18 (New King James). 
created. ${ }^{4}$ The problem is not limited to antibiotics. Variants of the human immunodeficiency virus (HIV) develop resistance to anti-retroviral drugs. ${ }^{5}$ Antifungal agents face similar challenges. Even cancer cells may develop resistance to pharmaceuticals. ${ }^{6}$ Tens of thousands of Americans are dying every year from drug-resistant infections. ${ }^{7}$ Some pharmaceutical knowledge is therefore exhaustible, and after patent expiration the public domain may receive a drug which is no longer useful. For these drugs, the public domain vanishes. ${ }^{8}$

Unwilling to live in a post-antibiotic era, society deploys two strategies against resistance. One strategy is research and development (R\&D), allocating resources to discover new drugs. The other strategy is conservation: reducing demand through health promotion and sanitation,

4. See D.J. Austin et al., The Relationship Between the Volume of Antimicrobial Consumption in Human Communities and the Frequency of Resistance, 96 Proc. NAT'L ACAD. SCI. 1152, 1152 (1999) (noting that the precise quantitative relationships are unknown at present); David M. Livermore, Bacterial Resistance: Origins, Epidemiology, and Impact, 36 CliniCAL InfEC Tious Diseases s11 (Supp. I 2003). Bacteria, viruses, parasites, and fungi are the major sources of infectious diseases that may develop resistance to therapies. Livermore, supra, at s11. For an economic model of biological resistance, see Timo Goesch1 \& Timothy Swanson, On Biology and Technology: The Economics of Managing Biotechnologies (Fondazione Eni Enrico Mattei, Working Paper No. 42, 2003), at http://www.feem.it/NR/rdonlyres/ 2066F059-6A8F-434D-B750-1AC996B9A421/721/4203.pdf(last visited Aug. 30, 2005). But see Roger L. White, How Do Measurements of Antibiotic Consumption Relate to Antibiotic Resistance?, in Antibiotic Policies: Theory and Practice 76 (Ian M. Gould \& Jos W. M. Van Der Meer eds., 2005) [hereinafter Antibiotic Policies] ("Proving a causal relationship between the use of antimicrobials and development of resistance is very difficult; however, they have been linked by a substantial amount of evidence.").

5. World Health Org. (WHO), Scaling Up Antiretroviral Therapy in Resource-Limited Settings: Treatment Guidelines for a Public Health Approach 5 (2003), available at http:// www.who.int/hiv/pub/prev_care/en/arvrevision2003en.pdf(last visited July 10, 2005); SANJAY PUJARI ET al., Safety and Long-Term Effectiveness of Generic Fixed-Dose Formulations of NevirapineBased HAART Amongst Antiretroviral-NaÏve HIV-Infected Patients IN India 3 (Nov. 18, 2003) (background document for WHO meeting on Fixed-Dose Combinations for HIV/AIDS, Tuberculosis, and Malaria). For recent news accounts concerning potential AIDS resistance, see Marc Santora \& Lawrence K. Altman, Charges of Premature Action Shadow AIDS Case Disclosure, N.Y. Times, Feb. 21, 2005, at A17; and James Meikle, Warning of Drug Resistance, THE GUARDIAN (London), July 29, 2005 (stating that $27 \%$ of British HIV patients develop resistance to at least one ARV within six years of starting treatment).

6. For these cancer cells, the negative externality of waste is probably not present unless the resistant cancer cells or genes spread to other individuals, akin to infection. See discussion infra Section II.A (describing the waste externality).

7. Greg Groeller, Wyeth Has New Type of Intravenous Antibiotic, WALL ST. J., June 1, 2005, at A16.

8. "Resistance limits the effectiveness of antibiotics over time and therefore decreases a drug's long-term profitability. Antibiotics and other antimicrobials are the only drugs where extensive use leads to loss of benefit." BAD BUGS, supra note 1, at 17. 
stewarding available antibiotic drugs, and prolonging their useful therapeutic lives.

Both strategies face daunting challenges. R\&D may encounter increasingly diminishing returns, since the easiest biological targets may have already been found. Echoing Malthus, some fear that science will be unable to keep ahead of resistance. ${ }^{9}$ Conservation faces the unhappy prospect of fighting an eternal rear-guard action, never winning, but merely postponing the inevitable. ${ }^{10}$ Even the best conservation schemes may eventually fall to resistance. Demand for antibiotics cannot be reduced to zero. Combating antibiotic resistance may be analogized to running on a treadmill: $R \& D$ is learning how to run faster, while conservation is slowing the treadmill down. ${ }^{11}$

This Article explores the vanishing public domain of exhaustible pharmaceutical knowledge. After laying appropriate theoretical foundations, it critiques several prominent proposals (by Eric Kades, Richard P. Wenzel, and the Infectious Diseases Society of America) that recommend solving the antibiotic resistance dilemma through strengthening Intellectual Property (IP) law. This Article takes the opposite approach, recommending the restoration and conservation of the public domain so that the fruits of pharmaceutical innovation remain the common heritage of humanity instead of becoming the exclusive property of the rich.

9. If resistance is a steady state based upon utilization, but discovery faces diminishing returns, at some point the curves cross and resistance wins. Livermore, supra note 4, at s18 (noting the positions taken by optimists and pessimists). This argument echoes the famous "geometric v. arithmetic" progressions described by Thomas Malthus. See generally Thomas R. Malthus, An Essay on the Principle of Population (1798), available at http://www.econlib.org/library/Malthus/malPop.html.

10. Some conservation strategies appear to work with some strains, but much work needs to be done to understand exactly how and why certain conservation strategies work or not. See, e.g., the major review study conducted by Parrino which found that many conservation strategies were effective in reducing inappropriate antibiotic utilization. Thomas A. Parrino, Controlled Trials to Improve Antibiotic Utilization: A Systematic Review of Experience, 1984-2004, 25 PHARmacotherapy 289, 289-98 (2005); see also Jerry Avorn \& Daniel H. Solomon, Cultural and Economic Factors that (Mis)Shape Antibiotic Use: The Nonpharmacologic Basis of Therapeutics, 133 AnNALs of InTER NAL Med. 128, 128-35 (July 18, 2000) (describing effective programs to reduce unnecessary prescriptions of antibiotics). See Livermore, supra note 4 , at s19-20.

It is salutary to emphasize how much remains unknown. Does drug cycling have positive effects, or does it lead to the accumulation of multidrug-resistant strains? At what prevalence of resistance should empirical therapy be changed in different types of infection? To what extent does combination therapy militate against resistance (except in the case of tuberculosis, where its value is beyond dispute)?

Id. at $\mathrm{s} 20$.

11. The analogy is adapted from Goeschl \& Swanson, supra note 4, $\S$ 1-2. 


\section{Exhaustible Pharmaceutical Knowledge}

\section{A. The Domains of the Patent Bargain}

Patent law is the public creation of private goods. The public creates IP law which creates the private domain of intellectual property rights and duties. ${ }^{12}$ IP law permits the innovator to appropriate extra profits (rents) for a limited period of time. Operating under the structure of law-based appropriation, ${ }^{13}$ private IP goods are first created and then traded.

Patent law is also the private creation of public goods. Private firms create knowledge that they may choose to disclose in a patent application. If undisclosed, the knowledge remains in the private domain, protected by contract and trade secrecy laws. If the knowledge is disclosed through a patent application, it first enters the patent domain, where use of the knowledge is regulated to support pharmaceutical rent appropriation. ${ }^{14}$

After patent expiration or the publication of the trade secret, disclosed knowledge fully enters the public domain as public law support for rent appropriation ends. ${ }^{15}$ Some knowledge bypasses the patent domain altogether

12. While we have grown accustomed to speaking only of intellectual property rights, the Hohfeldian framework should apply to intellectual property in a fashion similar to personal or real property. Intellectual property duties deserve a more detailed analysis in a future article. For Hohfeld's classic work, see Wesley Newcomb Hohfe ld, Fund amental Legal Conceptions 35-64 (Walter Wheeler Cook ed., 1919).

13. Law-based appropriation is much broader than patent, copyright, and trademark law. In the pharmaceutical industry in particular, many laws affect appropriation and rent extraction. See generally Kevin Outterson, Pharmaceutical Arbitrage: Balancing Access and Innovation in International Prescription Drug Markets, 5 Yale J. Health Pol'y L. \& Ethics 193, 206-16 (2005) [hereinafter Pharmaceutical Arbitrage].

14. Knowledge in the patent domain has some public value. Once disclosed, knowledge (or the good produced under patent) can form the basis for research, work-arounds, sequential invention, and reverse engineering, subject to possible actions alleging infringement. Inadequate disclosures weaken the value of the patent domain and force rivals to reverse engineer in order to discover the undisclosed.

15. For this Article, knowledge is in the public domain to the extent it is disclosed but lacks lawbased appropriation. Knowledge in the patent domain is likewise disclosed but enjoys law-based appropriation from several possible sources, including patent law. Doctrines such as fair use or compulsory licensure are intellectual property duties, fine tuning the degree of appropriation during the patent domain. One advantage of this approach is that it focuses the question on "how much appropriation is enough?"; a question too rarely asked in pharmaceutical patent policy. See Pharmaceutical Arbitrage, supra note 13, at 220 . 
and is created for public use in the first instance. ${ }^{16}$ Just as all rivers flow into the sea ${ }^{17}$ all knowledge eventually flows into the public domain.

The patent and public domains are socially balanced in the patent bargain, ${ }^{18}$ which offers the inventor a period of appropriation (an IP right) in exchange for disclosing the invention to the public (an IP duty). When knowledge is in the patent domain, the inventor enjoys legal support for appropriation, while the public receives the opportunity to purchase products that otherwise might not have been produced.

Knowledge in the public domain is a public good which shares two essential characteristics: nonrivalrous by nature and inappropriable by law. By its essential nature, knowledge is not diminished by joint or sequential use. For example, we may utilize the works of both Newton and Hawkins without rivalry; we may agree with Jefferson on this point ${ }^{19}$ without diminishing him in the least. ${ }^{20}$

Whether knowledge is appropriable is a matter of law. Public domain knowledge is available to all without rent extraction. No one is excluded (or excludable) absent the legal tools of appropriation. Public domain knowledge is especially valuable since it may be used without the deadweight losses and

16. Robert P. Merges, A New Dynamism in the Public Domain, 71 U. CHI. L. Rev. 183, 183 (2004). Merges cites several examples of private efforts to expand the public domain. The examples most relevant to pharmaceutical knowledge deny appropriation rents to upstream R\&D (DNA segments and computer operating systems) while laying the foundation for downstream appropriation (genomic drugs, Linux applications, and consulting). See id. at 186-93. Rents are shifted downstream, but nevertheless remain.

17. See Ecclesiastes 1:7. The geographic exception which proves the rule is the Great Basin, from which no surface water flows into any sea. A trade secret which is never disclosed (i.e., the recipe for Coke) might be the IP analogue.

18. The patent bargain is not the only possible theoretical justification for patent law, but it is one commonly used in U.S. jurisprudence.

19. See Letter from Thomas Jefferson to Isaac McPherson (Aug. 13, 1813), reprinted in 13 The Writings of ThOM AS JefFerson 333-35 (Andrew A. Lipscomb \& Albert Ellery Bergh eds., 1905).

He who receives an idea from me, receives instruction himself without lessening mine; as he who lights his taper at mine, receives light without darkening me. That ideas should freely spread from one to another over the globe, for the moral and mutual instruction of man, and improvement of his condition, seems to have been peculiarly and benevolently designed by nature . . incapable of confinement or exclusive appropriation. Inventions then cannot, in nature, be a subject of property. Society may give an exclusive right to the profits arising from them, as an encouragement to men to pursue ideas which may produce utility, but this may or may not be done, according to the will Id. and convenience of the society, without claim or complaint from anybody.

20. While knowledge is not destroyed through use, it may lose value because it is inappropriable. For example, market-moving financial information may lose its value quickly, particularly as market participants act on the information. This is a function of inappropriability, rather than exhaustion or rivalry. From a societal perspective, knowledge does not lose value through use but instead adds to the public domain. 
innovation thickets ${ }^{21}$ associated with law-based appropriation. For example, the Access to Knowledge (A2K) movement seeks a global treaty to maximize the value to humanity of nonrivalrous knowledge. A2K advocates call for permitting low- and medium-income communities to gain lower-cost or free access to knowledge. One example would be free distribution of medical journals in low- and middle-income settings. Essentially, A2K seeks to modify the legal structures of appropriation of knowledge, permitting greater appropriation by the poor instead of against the poor. ${ }^{22}$

In pharmaceutical markets, entering the patent domain means a new drug may become available to treat human illness. When a pharmaceutical patent is disclosed, the knowledge begins to enter the public domain in a limited sense. The information can be observed and understood by all, and may be used for further research. ${ }^{23}$ But the patent laws award to the owner exclusive patent rights for the commercial exploitation of the drug. Full entry into the public domain is delayed until after patent expiration. The patent domain in the U.S. persists for about 14 years, ${ }^{24}$ and then generic drugs are able to enter the market. At that point (or six months later), ${ }^{25}$ the pharmaceutical knowledge completes its journey into the public domain. ${ }^{26}$ In the public

21. See generally Michael A. Heller \& Rebecca S. Eisenberg, Can Patents Deter Innovation? The Anticommons in Biomedical Research, 280 SCI. MAG. 698, 698 (1998).

22. For information on A2K, see www.cptech.org/a2k/ (last visited June 21, 2005). A draft A2K treaty may be found at Access to Knowledge, Treaty on Access to Knowledge, May 9, 2005, at http:// www.cptech.org/a2k/consolidated text-may9.pdf. A2Kis one issue raised by the World Intellectual Property Organization (WIPO) Development Agenda.

23. See supra note 14. See generally Merck KGaA v. Integra Lifesciences I, Ltd., No. 03-1237, 2005 U.S. LEXIS 4840 (June 13, 2005).

24. The exclusive marketing period is shorter than the 20-year patent term because several years pass from the patent date until the drug is approved for marketing. By the late 1990s, the U.S. pharmaceutical exclusive marketing period was approximately 14 years. Cong. Budget Office, How Increased Competition from Generic Drugs Has Affected Prices and Returns in the Pharmaceutical INDUSTRY 45-48 (1998) [hereinafter INCREASED COMPETITION]. There is some evidence that the period is longer for recent antibiotics. For the last two novel antibiotics approved by the FDA (Zyvox/linezolid and Cubicin/daptomycin), the exclusive marketing period indicated by the FDAORANGE BOOK is 14 to 21 years for Zyvox and 13 to 16 years for Cubicin. The patent and marketing exclusivity data for linezolid and daptomycin are found in the FDA ORANGE BOoK, which is available at http://www.fda.gov/cder/ob/default. htm (current through July 2005).

25. First-mover generic companies receive 180 days of generic exclusivity, which prolongs appropriation of pharmaceutical rents for both companies by preventing market entry by rivals during the period. Federal Food, Drug, and Cosmetic Act, 21 U.S.C. § 355(j)(5)(B)(iv) (2000).

26. See InCREased Competition, supra note 24, at xii-xiii. The patent holder continues to earn pharmaceutical appropriation rents even after generic entry. These continued rents are supported by goodwill, marketing, trademarks, and other intangibles. After patent expiration, many brand-name drugs lose some market share, but actually increase in price (the so-called generic paradox). Incorporating these facts into the model transforms the bright line of patent expiration into a fuzzy post-patent period of 
domain, the wonders of pharmaceutical innovation become freely available to all. This is the great moment of payoff for global health.

Perhaps a 14-year layover in the patent domain provides a reasonable balance between innovation and access. Rich consumers pay for and receive the latest innovations ( 2005 medicine), while the poor might well be satisfied with the less effective, but much less expensive, 1991 all-generic pharmacopoeia. ${ }^{27}$ The World Health Organization (WHO) Essential Medicines List, which historically excluded expensive patented medicines, implicitly accepted the 14-year gap for the poor. ${ }^{28}$

A 14-year lag is one thing; waiting for eternity is another. The patent bargain has been breached if a lifesaving drug is withheld from the poor because it remains in the patent domain or if the drug is exhausted through antibiotic resistance by the time it reaches the public domain. The rich will have consumed a valuable resource, while the poor are left with nothing except a cruel memory of a fading hope. ${ }^{29}$

declining rents or rent truncation. Rent truncation can also occur prior to patent expiration, either through competition from a patented follow-on ("me-too") drug, or by public legal restrictions on marketing and reimbursement. See id.

27. The Earth Institute's 2004 report adopts this position for cardiovascular medications because "multiple, cheap medications are now available. Pharmaceuticals in nearly every class of drug used for [cardiovascular disease] are now off patent. There is no need to wait for a global trade agreement." Stephen leeder et al., A Race Against Time: The Challenge of Cardiovascular Disease in Developing EConomies 73-74 (2004). Lipitor would be a prominent counterexample. The report also highlights the marginal cost-effectiveness of some newer pharmaceuticals in resource-constrained settings. See id. at 74 .

28. The World Health Organization (WHO) Model List of Essential Medicines (14th ed. March 2005) does not say so clearly, but many commentators have identified the historic exclusion of many patented drugs due to cost. See, e.g., Jillian Clare Cohen, Developing States' Responses to the Pharmaceutical Imperatives of the TRIPS Agreement, in THE ECONOMICS OF EsSENTIAL MEDICINES 125 (Brigitte Granville ed., 2002) [hereinafter Essential Medicines]; Oxfam, Fatal Side Effects: Medicine Patents Under the Microscope, in Essential Medicines, supra, at 88; Anna Thomas, Street Price: A Global Approach to Drug Pricing for Developing Countries, in Essential Medicines, supra, at 278; Ellen 't Hoen, TRIPS, Pharmaceutical Patents, and Access to Essential Medicines: A Long Way From Seattle to Doha, 3 CHI. J. InT'L L. 27, 34 (2002); Richard Laing et al., 25 Years of the WHO Essential Medicines Lists: Progress and Challenges, 361 The LANCet 1723, $1723-29$ (May 17, 2003) (noting that in 1999 only around 15 of the 306 products on the WHO list were patented), available at www.thelancet.com. But see Amir Attaran, How Do Patents and Economic Policies Affect Access to Essential Medicines in Developing Countries?, 23 HeAlth AfF. 155, 160 (2004) (claiming that the WHO never kept patented products off of the Model List). Patented drugs were largely absent from the list due to cost, not just patent status per se. But of course, patent status influenced cost, and, thus, placement on the list.

29. This statement is somewhat hyperbolic. Penicillin resistance was widespread 25 years after introduction, but methicillin resistance took longer to appear. See BAD Bugs, supra note 1, at 10. Methicillin resistance at 13 years was approximately $2 \%$; at 41 years, resistance was $57.1 \%$. Id. Newer classes of antibiotics may suffer significant incidence of resistance in even shorter timeframes, perhaps due to cross-resistance against existing therapies. Ramanan Laxminarayan, Introduction: On the Economics 
People living with AIDS in resource-poor settings have waited for a decade for access to lifesaving anti-retrovirals (ARVs). Almost six million people in low- and middle-income populations are dying for ARVs today; only $15 \%$ of the people needing ARVs in low- and middle-income countries received them as of June $2005 .^{30}$ Just as ARV treatment in low- and middleincome countries is beginning to scale up, ${ }^{31}$ resistance to first-line therapy is building. ${ }^{32}$ Second-line ARVs including protease inhibitors ${ }^{33}$ are not generally available in generic or fixed-dose combination (FDC) form. ${ }^{34}$ Patented second-line therapies are very expensive in low-and middle-income countries.

of Resistance, in Battling Resistance to Antibiotics and Pesticides: An Economic Approach 9 (Ramanan Laxminarayan ed., 2003) [hereinafter Battling Resistance]. Fluoroquinolone-resistant Pseudomonas aeruginosa reached over a 30\% incidence of resistance within 14 years of introduction. BAD BugS, supra note 1, at 11 . Vancomycin-resistant enterococci reached $25 \%$ resistance rates in the same timeframe. Id. Antiretrovirals for AIDS appear to be developing resistance more quickly than methicillin. See Sheila M.L. Waugh \& William F. Carman, Strategies for the Rational Use of Antivirals, in ANT IBIOTIC PoliCIES, supra note 4, at 331-42 (describing how RNA viruses such as AIDS mutate much more quickly than DNA viruses); Lawrence K. Altman, AIDS Drugs' Fast Rise in Asia Risks Resistant Strains, N.Y. TIMES, July 8, 2004, at A3 (citing a report by the American Found ation for AIDS Research (AmFAR)). Of course, resistance to particular strains does not fully exhaust the drug; it only makes it less useful.

30. WhO, Progress on Global Access to HiV Antiretroviral Therapy: An Update on “3 BY 5," at 13 (June 2005), available at http://www.who.int/3by5/fullreportJune2005.pdf (last visited Sept. 29, 2005). As of June 2005, approximately 1 million people living with AIDS were receiving ARV treatment in low- and middle-income countries. $I d$. at 7. Approximately 6.5 million people currently are untreated and will die within two years absent ARV therapy. Id. at 13.

31. See Ben Hirschler, Reuters, Generic Drugs Key to Uphill AIDS Fight, WHO Says (June 21, 2005) (describing scale-up efforts to increase access to ARVs in low-income populations), available at http://www.alertnet.org/thenews/newsdesk/L21675875.htm (last visited June 22, 2005).

32. A. Winston \& J. Stebbing, New Drugs for Old, 10 J. HIV THERAPY 11, 11-16 (Mar. 2005).

33. Protease inhibitors are a separate class of ARVs, typically used as a first-line treatment in combination with Nucleoside Reverse Transcriptase Inhibitors (NRTIs) and Non-Nucleoside Reverse Transcriptase Inhibitors (NNTRIs), or as a second-line treatment when NRTIs and NNTRIs have failed due to resistance or clinical intolerance. See, e.g., B. Clotet, Strategies for Overcoming Resistance in HIV-1 Infected Patients Receiving HAART, 6 AIDS Rev. 123, 123-30 (July-Sept. 2004); Amanda Mocroft et al., The Use of and Response to Second-Line Protease Inhibitor Regimens: Results From the EuroSIDA Study, 15 AIDS 201, 201-09 (2001); B.T. Roge et al., Drug Resistance Mutations and Outcome of Second-Line Treatment in Patients with First-Line Protease Inhibitor Failure on Nelfinavir-Containing HAART, $4 \mathrm{HIV}$ MED. 38, 38-47 (Jan. 2003).

34. A recommended second-line regime is TDF $+d d I+L P V / r$. Ellen 't Hoen, Médecins Sans Frontières (MSF) Access to Essential Medicines Campaign, Presentation to the European Parliament Comm. on Int'l Trade, Hearing on TRIPS and Access to Medicines 6 (Jan. 18, 2005), available at http://www.accessmed-msf.org. Second-line treatments also are important in conservation of resistance, and there is no FDC available for second-line treatment as a result of the patents. See Alexandra Calmy et al., First-line and Second-line Antiretroviral Therapy, 364 THe LANCET 329, 329 (2004), available at http://www.thelancet.com. 
Even with voluntary discount programs, second-line therapies cost 10 to 26 times more than the first-line drugs. ${ }^{35}$

Nor is this problem limited to AIDS. Many anti-malarial drugs are no longer effective against Plasmodium falciparum after decades of use. ${ }^{36}$ The American Enterprise Institute alleges that ineffective off-patent malaria drugs (such as chloroquine) are routinely provided to developing countries by global donors, while a more expensive patented drug combination is underutilized. ${ }^{37}$ Malaria annually afflicts 300 million to 500 million people, killing more than 1 million every year. ${ }^{38}$ Tuberculosis kills more than 2 million people per year, and perhaps one-third of the world's population is infected. ${ }^{39}$ Multiple-drug resistant tuberculosis is a major global disease, requiring the much more expensive Directly-Observed Treatment, Short-course (DOTS). ${ }^{40}$ Similar stories could be told for the cervical cancer vaccine or chronic conditions such as heart disease or depression. ${ }^{41}$ Whenever an innovative drug receives a patent, the pattern may be repeated.

During the patent domain layover, millions of people may die, at least in part, because they could not afford to pay the pharmaceutical appropriation

35. See 't Hoen, supra note 34, at 5-6 (explaining that second-line treatment in low-income countries costs about US\$3950 per year, and is as high as US\$5000 per year); see also N. Kumarasamy, Comment, Generic Antiretroviral Drugs-Will They Be the Answer to HIV in the Developing World?, 364 The LANCET 3, 3 (2004), available at www.thelancet.com; Médec ins SAns Frontières, Untangling The Web of Price Reductions: A Pricing Guide for the Purchase of ARVs for Developing Countries 5 (6th ed. 2004) (identifying factors contributing to the price decrease for some first-line antiretrovirals), available at www.accessmed-msf.org.

36. See Roger Bate, Giving the Poor Drugs that Don't Work, Dec. 2, 2003, http://www.aei.org/ publications (last visited July 10, 2005); cf. Bernard Pécoul et al., Access to Essential Drugs in Poor Countries: A Lost Battle?, 281 JAMA 361, 363-65 (1999)(providing specific examples of resistant strains in tropical diseases).

37. Bate, supra note 36 . Malarial resistance to chloroquine runs as high as $80 \%$ in some locations; an alternative drug, Artemisinin, is more expensive and underutilized, especially in combination therapy. See id. But see Jack C. Chow, M.D., Letter to the Editor, WHO, Global Fund Get Best Medicine Available, WaLl. St. J., Jan. 26, 2004, at A15 (responding to the Jan. 21, 2004 editorial entitled WHO's Bad Medicine, which describes a Lancet article criticizing WHO for not supplying poor countries with effective treatments, by noting that $\mathrm{WHO}$ and the Global Fund are working to provide Artemisinin combination therapy).

38. Global Forum for Health Research, The 10/90 Report on Health Research 2003-2004, at 215 (2004), available at http://www.globalforumhealth.org.

39. Id. at 193

40. Marilyn Chase, Drug-Resistant TB Hits New Group, Wall St. J., June 8, 2005, at D13; see also WHO, DOTS, http://www.who.int/tb/dots/en (last visited July 4, 2005) (providing information pertaining to DOTS).

41. Pharmaceutical Arbitrage, supra note 13, at 248-50. 
rent. ${ }^{42}$ Denying such drugs to low-income populations sacrifices access and human rights on the doubtful altar of innovation. ${ }^{43}$

\section{B. Exhaustible Pharmaceutical Knowledge}

The patent bargain assumes that information entering the public domain remains there. ${ }^{44}$ This static assumption is not always appropriate when considering dynamic living systems. Some pharmaceutical knowledge is exhaustible (rivalrous) due to evolutionary response. ${ }^{45}$ When pharmaceutical knowledge is exhaustible, it loses its nonrivalrous character. This Article identifies this condition as "Exhaustible Pharmaceutical Knowledge" or EPK. $^{46}$

While generalizations are dangerous in this area of microbiology, resistance generally proceeds more quickly the more a drug is utilized. ${ }^{47}$

42. See generallyid. at 250-75. A newer class of antibiotics-fluoroquinolones-works well with drug resistant strains, but these drugs are expensive, leaving the poor with less-effective classes of antibiotics. Oxfam, supra note 28 , at 88.

43. Doubtful in the sense that innovation could have been protected without such an awful sacrifice. Innovation and access are not necessarily in a zero-sum game. See infra Section II.C.

44. It is of course possible to privatize elements of the public domain at a later date. Two prominent examples would be the English Enclosure Movement and the U.S. Homestead Act which opened the American West to white settlement. Privatization might occasionally be warranted for rivalrous goods such as land for the reasons described by Garrett Hardin and others. See, e.g., Garrett Hardin, The Tragedy of the Commons, SCI. MaG., Dec. 13, 1968, at 1243-48; Randall R. Dipert, Sidestepping the Tragedy of the Commons, in The Commons: Its Tragedies and Other Follies 27 (Tibor R. Machan ed., 2001). Removing nonrivalrous knowledge from the public domain requires special pleading, such as controlling the spread of nuclear technology in an antiterrorism program. Professor Kades suggests withdrawing expired antibiotic patents from the public domain, retroactively restoring the patent as a conservation measure for exhaustible pharmaceutical knowledge. Eric Kades, Preserving a Precious Resource: Rationalizing the Use of Antibiotics, 99 Nw. U. L. REv. 611, 652-53 (2005). His prime candidate for privatization is vancomycin: "a critical antibiotic of last resort for some lethal infections, that went offpatent decades ago." Id. at 652 . Vancomycin is an interesting choice, since the vast majority of U.S. consumption (by kilograms) is by injection rather than oral tablets. Herbert A. Kirst, Diane G. Thompson \& Thalia I. Nicas, Historical Yearly Usage of Vancomycin, 42 ANTIMICR oBial AgENTs \& CHEMOTHERAPY 1303, 1303-04 (May 1998) (letter to the editor). Vancomycin is an institutional drug, generally used in hospital ICUs, quite different from the ambulatory examples of wanton overuse proffered by Kades.

45. See supra note 4 (listing sources describing antibiotic resistance).

46. Most of the antibiotic economics literature chooses the word exhaustible as opposed to rivalrous. I follow the literature, but with reservations. Exhaustible may falsely imply that the resource is finite. Antibiotics are not finite, but may be created through innovation. In certain circumstances, antibiotics may also be renewable, making them more analogous perhaps to fisheries than finite mineral deposits. Exhaustible also implies a binary analysis, available or exhausted, whereas microbes develop resistance progressively and cyclically, both geographically and with respect to different drugs.

47. "It remains plausible (but unproven) that a generalized reduction in prescribing may lead to a reduction in resistance prevalence." Livermore, supra note 4, at s19. 
Patient compliance is also an important factor, ${ }^{48}$ as is the location and intensity of use. ${ }^{49}$ Many factors affect the exhaustion rate of EPK and whether resistance can be reversed. Conserving EPK to stave off resistance is a complicated affair but an important approach if the pace of new drug introductions has slowed. ${ }^{50}$

Thus far, discussions of EPK have focused upon discrete packets of knowledge, usually embodied in the patents listed in the FDA ORANGE BOOK ${ }^{51}$ for a particular drug. However, pharmaceutical knowledge may potentially be exhaustible in a global sense. Some biologists believe that we have already harvested the low-hanging fruit of easily discoverable antibiotics. ${ }^{52}$ Some suspect that perhaps the tree itself is bare. ${ }^{53}$ If the number of possible antibiotic targets is finite, then resistance will eventually master them all. This problem is not fundamentally changed if one discounts the word finite but acknowledges that diminishing returns and increasing costs can make the discovery of additional EPK economically impractical. ${ }^{54}$ In a global sense, EPK may be a finite resource like fossil fuels.

The implications are profound. We might be content to allow the market to price fossil fuels, but for EPK, price-rationing is unacceptable. ${ }^{55}$ If EPK is

48. Usage does not necessarily result in resistance in a linear fashion, but many factors are involved, including compliance with conservation protocols and the use of combination therapies. See infra Section II.D.6. The primary point is that widespread, global use of an exhaustible drug will probably advance the onset of resistance. See Livermore, supra note 4, at s11. Studies asserting linear associations at national scales might well mask heterogeneity at community, institution, or individual scales. See, e.g., Werner C. Albrich et al., Antibiotic Selection Pressure and Resistance in Streptococcus pneumoniae and Streptococcus pyogenes, 10 EMERGING INFEC TIOUS DisEASES 514, 515 (2004) (finding an "almost linear" association between total volume of antibiotic consumption and prevalence of penicillin-nonsusceptible Streptococcus pneumoniae at national levels).

49. Fiona M. MacKenzie \& Ian M. Gould, Quantitative Measurement of Antibiotic Use, in Antibiotic Policies, supra note 4, at 105 ("Although the greatest use in human medicine is in the community, it is the intensive use of antibiotics in our hospitals that has the greatest impact on resistance.").

50. Conservation of EPK is considered infra Section II.D. For economic models of resistance, see Laxminarayan, supra note 29.

51. FDA ORANGE BooK, supra note 24.

52. The phrase is attributed to Steven Projan of Wyeth Pharmaceuticals. Martin Leep, Antibiotics: A Shot in the Arm, 431 NATURE 892-93 (2004).

53. Office of Tech. Assessment, U.S. Cong., Impacts of Antibiotic-Resistant Bacteria, OTA-H-629, at 101 (1995) ("The fact that [the] U.S. Food and Drug Administration (FDA) approved no new antibiotics in 1994 has led to fear that there are no new ideas for antibiotics or that there are insufficient financial incentives ....”, available at http://www.wws.princeton.edu/ota/disk1/1995/9503 n.html.

54. Gardner Brown \& David F. Layton, Resistance Economics: Social Cost and the Evolution of Antibiotic Resistance, 1 Env'T \& Dev. Econ. 349, 351 (1996).

55. If the AIDS treatment crisis has taught us anything, we know that lifesaving medications cannot be withheld from the poor merely because of their poverty. 
finite like fossil fuels, investments in traditional drug discovery R\&D only hasten the day of exhaustion, and conservation must be given first priority. Under these conditions, only conservation expands the total treatment capacity over time. R\&D priorities may need to be directed away from traditional drug discovery and greater emphasis placed on conservation.

\section{Common Pool Resources}

Exhaustible goods which are inappropriable represent the paradigm case of the tragedy (or fable) ${ }^{56}$ of the commons: the overgrazed common pasture. ${ }^{57}$ This Article employs the term common pool resources, which brackets the question of whether the commons were tragic or comedic. ${ }^{58}$

Some common pool resources are effectively managed through consensual coordination mechanisms. ${ }^{59}$ Others are coordinated through government action. ${ }^{60}$ Still others are governed by private property rights: The inappropriable is made appropriable by law. Sometimes the law permits common pool resources to be privatized. Property law saves the commons by destroying it.

Some legal duties are also imposed therewith. The new property owner may be expected to pay the public for the resources withdrawn from the common pool. The owner of the newly propertized and privatized resource should also comply with general property laws. ${ }^{61}$ Common pool resources

56. Empirically, the "tragedy" does not always occur, such as when users of the commons cooperate without carving the resource up into property fiefdoms. See generally Carol Rose, The Comedy of the Commons: Custom, Commerce, and Inherently Public Property, 53 U. CHI. L. Rev. 711 (1986).

57. Pastures are renewable resources, dampening their rivalrous natures until an ecological tipping point is reached. Even if the resources are not degraded through gross overuse, conservation by a single owner might well result in supra-optimal production. For perfectly non-renewable resources (e.g., propulsion fuel on Apollo 13), rivalry is apparent much sooner. Some antibiotic resistance may be partially reversible, placing EPK in the renewable resource category, akin to forests or fisheries. Livermore, supra note 4, at s18-19; see also Gary V. Doern et al., Antimicrobial Resistance among Streptococcus pneumoniae in the United States: Have We Begun to Turn the Corner on Resistance to Certain Antimicrobial Classes?, 41 Clinical Infectious Diseases 139, 139 (2005) ("Trend analysis since 1994-1995 indicated that rates of resistance to B-luctams, macrolides, tetracyclines, TMP-SMX, and multiple drugs have either plateaued or have begun to decrease [but not fluroquiniolones]."); infra note 191. But see Kades, supra note 44, at 619-21.

58. Public fisheries and forests are examples of common pools. Fisheries and forests are rivalrous, but can be indefinitely renewable if properly managed.

59. See generally Robert C. Ellickson, Order Without law: How Neighbors Settle Disputes (1994); Elinor Ostrom, Governing the Commons: The Evolution of Institutions for Collective Action (1990); Rose, supra note 56.

60. Pollution control is a classic example. The environment is the common pool.

61. Professor Michael Carrier has analyzed whether common law property norms might limit 
which have been privatized should still be subject to public regulation (the imposition of duties) for negative externalities such as pollution or nuisance.

EPK in its natural (anarchical, pre-legal) state is a common pool resource, both rivalrous and inappropriable. IP law transforms EPK into private property, withdrawing a common pool resource and creating a private property interest. The common pool of knowledge has been augmented through innovation $^{62}$ and then privatized in a patent. The law which permits propertization encourages innovation and the creation of additional common pool EPK resources. The pie gets bigger when it is sliced and sold. ${ }^{63}$

However, patents are not perpetual property rights. ${ }^{64}$ Under current law, patents ${ }^{65}$ are technically valid for 20 years, ${ }^{66}$ with an effective patent life for pharmaceuticals of about 14 years. ${ }^{67}$ Time-limited property rights for EPK create interesting externalities. These externalities occur both before and after appropriation and in both the patent and public domains. They are largely negative, which calls for the imposition of Pigovian taxes when property

intellectual property rights in a similar vein. See generally Michael A. Carrier, Cabining Intellectual Property Through a Property Paradigm, 54 Duke L.J. 1 (2004).

62. The ability to create additional knowledge through $R \& D$ is a major departure from the paradigm case of the finite and exhaustible commons, as shall be explored below.

63. My children would be pleased.

64. Unless Professor Kades carries the day.

65. In addition to patents, pharmaceuticals may enjoy "exclusive marketing rights" under various FDA incentives. 21 U.S.C. $\S \S 360 a a-360$ ee (2000). For the purposes of this Article, exclusive marketing rights are identical to patents in that they permit appropriation by the innovator. In lieu of repeating "patents and exclusive marketing rights," this Article will use the more general term "patents" unless the context clearly requires otherwise.

66. 35 U.S.C. $§ 154(a)(2)$ (2000); Agreement on Trade-Related Aspects of Intellectual Property Rights, 33 I.L.M. 81 (1994) [hereinafter TRIPS or TRIPS Agreement]. The United States implemented the World Trade Organization (WTO) agreements in the Uruguay Round Agreements Act, Pub. L. No. 103-465, 108 Stat. 4809 (1994). TRIPS permitted many developing countries to implement the agreements on a delayed basis. TRIPS, 33 I.L.M. 81, arts. 65-66. Most developing countries must implement the TRIPS Agreement by January 1, 2005, but the 30 "least developed countries" (LDCs) may defer full implementation for pharmaceutical products until 2016. WTO, Doha WTO Ministerial 2001, Declaration on the TRIPS Agreement and Public Health, WT/MIN(01)/DEC/2, 7 (Nov. 14, 2001) [hereinafter Doha Declaration on TRIPS]. Despite these concessions, all but three of Africa's LDCs have already adopted patent laws for pharmaceuticals. Phil Thorpe, Study on the IMPLEMentation of the TRIPS Agreement by Developing Countries 1 (Comm'n on Intellectual Prop. Rights, Study Paper No. 7), at http://www.iprcommission.org/graphic/documents/study_papers.htm (last visited July 10, 2005). TRIPS merely sets minimum periods of IP protection; the United States can still unilaterally extend patent protection and has done so with copyright. See, e.g., Eldred v. Ashcroft, 537 U.S. 186 (2003). WTO Members are also free to negotiate so-called "TRIPS-plus" agreements with additional provisions requiring protections in excess of the TRIPS Agreement's minimum standards. See, e.g., Kevin Outterson, Agony in the Antipodes: The Generic Drug Provisions of the Australia-USA Free Trade Agreement, 2 J. GENERIC Med. 316 (2005).

67. See supra note 24 . 
rights are concerned, or social management when the public domain is concerned. I now turn to those externalities in some detail.

\section{EPK EXTERNALITIES}

An externality arises when actors (firms or individuals) do not capture or account for all of the costs or benefits from their actions. A factory that belches pollution in an unregulated environment creates a negative externality. A drugmaker that sells a lifesaving pill for $\$ 1$ creates a positive externality: health at a bargain.

The language of externalities is another way of saying that the actor should take a broader point of view and account for social consequences more carefully. Decisions would be more rational if the actor accounted for all of the costs and benefits to all humanity. Microeconomics can be a God-game, thriving under conditions of omnipotency. ${ }^{68}$

Two broad solutions may respond to externalities: internalization and collective action. Internalization brings the costs or benefits directly to the actor, either by expanding the boundaries of the actor (enlarging the firm or creating a property right), ${ }^{69}$ or by imposing a Pigovian tax (e.g., on pollution) or Pigovian subsidy (e.g., tax credit for charitable giving) on the actor. Internalization is generally thought to be a "market-based" approach, since the actor directly responds to price and ownership forces. This characterization is perhaps too simplistic. Professor Kades posits two policy options for addressing the negative externalities of antibiotic use: Pigovian taxes ${ }^{70}$ and extended patent rights. ${ }^{71}$ Both options require government intervention into the free market, either through direct taxes or subsidies on various aspects of

68. As in the Sims, giving the player a God-level view of society's possibilities.

69. Expanding the boundaries of the firm can also permit pre-patent innovation in the private domain. See generally Oren Bar-Gill \& Gideon Parchomovsky, Intellectual Property Law and the Boundaries of the Firm 6 (Harv. Law School, John M. Olin Ctr. for Law, Economics, and Bus., Discussion Paper No. 480, 2004; U. of Pa. Law School, Law \& Econ. Research Paper Series, Research Paper No. 04-19,2004, available at http://papers.ssrn.com/sol3/papers.cfm?abstract_id=559195 (last visited July 10, 2005).

70. Kades, supra note 44 , at $635-43$.

71. Id. at 643-59. Kades was not the first to raise these issues. See, e.g., Ramanan Laxminarayan, Antibiotic Use in Animal Agriculture and the Economics of Resistance: How Broad Should the Scope of Antibiotic Patents Be?, 84 AM. J. AGRIC. ECON. 1287-92 (2002). Others have evaluated whether a patent monopolist will manage antibiotic resistance efficiently. See Carolyn Fischer, Does the Monopolist Care About Resistance?, in Battling Resistance, supra note 29, at 288-92; Douglas Noonan, An Economic Model of a Genetic Resistance Commons: Effects of Market Structure Applied to Biotechnology in Agriculture, in BAtTLIng Resistance, supra note 29, at 263-87. 
antibiotic use, or extended patent terms (patent monopolies) for useful antibiotics. Internalization should be seen for what it is: government intervention against a free market to alter incentives and change private behavior.

Externalities may also be addressed through collective action. Collective action requires atomistic actors to cooperate and move towards a common goal. $^{72}$ Extended families, civil society organizations, and trade associations are examples of collective action mechanisms, as is the democratic lawmaking process, which creates legal norms enforced by the state (e.g., pollution is illegal; free public education is mandatory). Collective action is generally regarded as a "regulatory" approach, although many of the possible collective action strategies hardly fit this label. Consider the efforts of hospitals to control antibiotic-resistant infections in intensive care units (ICUs). These efforts include sterilization, isolation, and careful use of antibiotics in the hospital. The modes of action include establishing hospital procedures, education of providers, benchmarking, accreditation, and peer review. The efforts of insurance companies and other payors to reduce inappropriate community prescribing of antibiotics are also collective action strategies which defy easy pigeonholing as "regulatory," at least in the typical sense of governmental top-down "command and control" regulation. ${ }^{73}$ For EPK, some collective action is collaborative; subsidiarity is respected when the people most closely affected by the situation and most intimately aware of the circumstances (such as the ICU staff) work out flexible and context-dependent local solutions.

With those thoughts in mind, the following sections describe externalities that affect EPK, together with possible approaches for resolving them.

\section{A. Waste}

A property owner with only one year remaining on a lease cannot be relied upon to manage the resource for the long term. Similarly, an EPK owner facing patent rent truncation may choose to maximize current sales rather than manage the resource for the long term. ${ }^{74}$

72. Collective action generally involves monitoring and enforcement mechanisms to minimize noncompliance.

73. Kades uses the label "command/control" in this context, analogizing medical education to reduce inappropriate prescriptions as akin to old-line communist command and control economies. Kades, supra note 44 , at 635 .

74. Truncation of patent rents may occur prior to patent expiration if patented follow-on innovation 
The common law addressed the problem of time-limited real property rights in the tort action of waste. The holder of a tenancy by years or a life estate could not clear-cut the forest or dismantle the manor house without standing to answer for waste to the landlord or holder of the reversion. By the year 1278, the Statute of Gloucester provided for treble damages for such waste. $^{75}$

In today's environment, pharmaceutical companies hold time-limited property rights much more valuable than any medieval manse. Evidence suggests pharmaceutical companies may be wasting EPK through overly aggressive marketing before the applicable drug joins the public domain. ${ }^{76}$ In this Article, the patent holder's proclivity towards short-term and firmbounded thinking when facing rent truncation shall be called waste. Waste is a negative externality. The global cost may well exceed many tens of billion dollars per year. ${ }^{77}$

The evidence of wasting behavior by pharmaceutical firms may be more anecdotal and intuitive than empirical at the present. ${ }^{78}$ As a possible example of waste (in the narrow sense described in this Article), consider Pfizer Inc.'s

("me-too" drugs) gain substantial market share. See Goeschl \& Swanson, supra note 4, § 2; Clem Tisdell, Exploitation of Techniques that Decline in Effectiveness with Use, 37 PuB. Fin. 428, 436 (1982) ("When there is free or common access to a technique that declines in effectiveness with use, it is likely to be exploited more quickly than is socially optimal."). Time-limited EPK is doubly subject to this effect.

75. See Statute of Gloucester, 1278, 6 Edw., c. 5.

76. The first novel antibiotic in decades was Zyvox/linezolid, introduced into the U.S. market in April 2000. Sales of Zyvox have escalated globally, becoming one of the best-selling antibiotics in the world. IMS Database, www.imshealth.com (2005) (on file with author); see also infra notes 85-97 and accompanying text.

77. If one assumes that marketing by patent holders advances antibiotic resistance by a few years, the direct cost would be the R\&D costs necessary to create the lost population-years of useful therapy. Given current levels of antibiotic R\&D, an order of magnitude estimate would be a few billion dollars per year. Indirect costs (such as lost Disability Adjusted Life Years (DALYs) from the lack of effective therapies after resistance) would be many times higher. In 1998, the Institute of Medicine estimated the U.S. cost of antibiotic-resistant bacteria to be at least $\$ 4$ to $\$ 5$ billion per year. INST. OF MED., Antimicrobial Resistance: Issues And Options 1 (Polly F. Harrison \& Joshua Lederberg eds., 1998). See generally Stephanie J. Dancer, The Real Cost of MRSA, in Antibiotic Policies, supra note 4, at 281-300 (exploring the direct and indirect costs of methicillin-resistant Staphylococcus aureus (MRSA)). Older cost estimates include $\$ 726$ million in 1998 dollars (about $\$ 1.5$ billion in 2004 dollars using IMS U.S. antibiotic sales as the price inflator) per year in the direct prescription cost for unnecessary antibiotics, Ralph Gonzales et al., Excessive Antibiotic Use for Acute Respiratory Infections in the United States, 33 CliniCAL INFEC TIOUS Diseases 757, 757-62 (2001), and an estimated \$1.3 billion dollar cost of hospitalacquired bacterial infections, using data from the early 1990s. Office of Technology Assessment, supra note 53 , at 2 .

78. See, e.g., Avorn \& Solomon, supra note 10, at 128 for non-empirical descriptions asserting that "[m]arketing campaigns directed at both physicians and patients further serve to increase demand, especially for newer, costlier [antibiotic] products." 
recently announced purchase of Vicuron Pharmaceuticals Inc. for \$1.9 billion. $^{79}$ Pfizer owns Diflucan, a former billion dollar-plus blockbuster antifungal drug that lost patent protection in early $2004 .{ }^{80}$ Pfizer introduced a follow-on patented drug, Vfend, but sales have been disappointing. ${ }^{81}$ Pfizer is purchasing Vicuron in order to fill its pipeline with profitable drugs to treat bacterial and fungal infections. ${ }^{82}$ A major drug in Vicuron's portfolio is dalbavancin, an antibiotic which is expected to be approved by the FDA within a year. ${ }^{83}$ While best medical practices might shelve dalbavancin for a long period of time until the social need is more compelling, Pfizer is expected to bring the drug to market immediately upon approval. ${ }^{84}$ One financial reason for urgency is the patent expiration on Pfizer's Zithromax/azithromycin. Zithromax is the best-selling antibiotic in the world in dollar terms and generic entry is expected shortly. ${ }^{85}$ In the 10 years prior to patent expiration, Pfizer's U.S. sales of Zithromax have increased steadily, from $\$ 104$ million in 1994 to $\$ 1.8$ billion in $2004 .{ }^{86}$ Over the same period, Zithromax has increased its market share among all antibiotics and within its class (macrolides) from $1.32 \%$ to $11.43 \%$ and from $15.10 \%$ to $68.77 \%$, respectively. ${ }^{87}$ It is apparently unknown whether the financial success of Zithromax is primarily due to Pfizer's marketing, the innate qualities of the drug, or the increased susceptibility of other macrolides. ${ }^{88}$ It is clear that bacterial resistance to macrolides is growing in the United States. ${ }^{89}$

79. Gustav Ando, Pfizer Buys Vicuron in U.S. \$2 bil. Deal as Fight Against Patent Expirations Continues, World Mkt. Analysis, June 16, 2005.

80. Id.

81. Id.

82. $I d$.

83. $I d$.

84. See id

85. Scott Hensley, Pfizer to Buy Infection-drug Maker, WALL St. J., June 17, 2005, at B5. A search of the FDA ORANGE BOOK disclosed no unexpired patents or periods of exclusivity for the tablet forms of Zithromax (azithromycin). See FDA Orange Book, supra note 24.

86. IMS Database, supra note 76 (year-to-date U.S. market sales data through October 2004).

87. Author's analysis of IMS data. See id.

88. For a discussion of the major macrolides, see S. Alvarez-Elcoro \& M.J. Enzler, The Macrolides: Erythromycin, Clarithromycin, and Azithromycin, 74 MA Yo Clin.Proc. 613, 613-34 (1999). A June 2005 MedLine search of titles and abstracts for the phrases "advertising or marketing" and "macrolides or antibiotics" revealed no relevant studies on this question. See Medline Plus, http://www.nlm.nih.gov/ medlineplus.

89. Edward O. Mason, Jr. et al., Macrolide Resistance Among Middle Ear Isolates of Streptococcus pneumoniae Observed at Eight United States Pediatric Centers: Prevalence of M and MLS Beta Phenotypes, 22 Pediatric Infectious Disease J. 623-27 (2003) (noting that erythromycin resistance increased from $15 \%$ in 1994 to $56 \%$ in 2000). Amazingly, U.S. erythromycin sales (in dollar terms) held their own during this period. IMS Database, supra note 76 (noting that 1994 U.S. sales $=\$ 15$ million; 2004 
A second potential example of waste could be one of the newest and most significant antibiotics, Tygacil/tigecycline. On June 15, 2005, the U.S. FDA approved Tygacil/tigecycline, the first antibiotic in a new therapeutic class, glycylcyclines. ${ }^{90}$ The patent holder, Wyeth Pharmaceuticals, faces a difficult choice between pressures to market Tygacil aggressively and the clinical demands of global EPK conservation. ${ }^{91}$ Tigecycline is a novel, wide spectrum antibiotic of significant value, ${ }^{92}$ but Wyeth's time-limited property right exposes this novel drug (and indeed the entire class of glycylcyclines) to waste. ${ }^{93}$ Wyeth has publicly announced that it views Tygacil as a blockbuster, with expected peak annual sales of $\$ 1$ billion. ${ }^{94}$ Wyeth touts its current bestselling antibiotic as a "workhorse" with expected 2005 annual sales in excess of $\$ 800$ million even after patent expiration..$^{95}$ The best medical approach for tigecycline might be to hold it completely off the market for many years, except for true emergency situations where no other drug would work. Expecting Wyeth to do so voluntarily seems too much; even a perpetual patent might not be sufficient.

U.S. sales $=\$ 17.7$ million $)$.

90. For a sample media report, see Marc Kaufman, FDA Approves New Antibiotic for Resistant Bacteria, WASH. Post, June 17, 2005, at A14. For the official FDA approval, see U.S. Food \& DrUG administration, Center for Drug Evaluation \& Research, A Catalog of FDa Approved Drug PRODUCTs, at http://www.accessdata.fda.gov/scripts/cder/drugsatfda/index.cfm?fuseaction=Search.Label_ ApprovalHistory\#apphist (last visited July 10, 2005). Some researchers consider tigecycline to be a tetracycline derivative, rather than a truly unique class. See, e.g., P.M. Shah, The Need for New Therapeutic Agents: What is the Pipeline?, 11 Clinical Microbiology \& Infection 36, 36-42 (Supp. 3, May 2005).

91. For the present, FDA approval has been granted only for the injectable form of Tygacil, which will limit its marketing potential.

92. A recent review article on tigecycline concluded that it may well be effective against a variety of resistant gram-positive organisms. M.W. Garrison, J.J. Neumiler \& S.M. Setter, Tigecycline: An Investigational Glycylcycline Antimicrobial with Activity Against Resistant Gram-Positive Organisms, 27 CLINICAL THERAPY 12-22 (2005).

93. As of June 22, 2005, the FDA OrangE BooK had not yet disclosed Wyeth's patents on Tygacil. See FDA ORANGe Book, supra note 24.

94. Geno Germano, Executive Vice President, Wyeth Pharmaceuticals, Presentation at the Deutsche Bank 30th Annual Health Care Conference 14 (May 3, 2005), available at http://phx.corporateir.net/phoenix.zhtml? $\mathrm{c}=78193 \& \mathrm{p}=$ irol-presentations (Wyeth Pharmaceuticals investors relations website) (last visited June 22, 2005); Groeller, supra note 7 ("Some analysts have predicted that Tygacil could ultimately mean $\$ 1$ billion in sales annually to Wyeth.").

95. Germano, supra note 94, at 12 (referring to Wyeth's combination IV antibiotic Zosyn (piperacillin/tazobactam)). The FDA ORANGE BOOK discloses no unexpired patents or exclusivity periods for Zosyn. See the FDA ORANGe BooK search results at http://www.accessdata.fda.gov/scripts/cder/ob/ docs/obdetail.cfm?Appl_No=050684\&TABLE1=OB_Rx(last visited June 22, 2005). Sales of Zosyn grew slowly from its introduction in 1993; U.S. sales first exceeded \$200 million in 2001. Since 2000, U.S. sales of Zosyn have increased more than $167 \%$. IMS Database, supra note 76. 
A third potential example is the April 2004 FDA approval of Ketek/telithromycin, the first antibiotic in a powerful new class known as ketolides. $^{96}$ Aventis Pharmaceuticals obtained approval to sell Ketek as a tablet for respiratory tract infections, a category with a history of inappropriate prescription patterns. ${ }^{97}$

Individuals may also waste EPK by inappropriately consuming antibiotics. Taking the drug might be clinically unnecessary, but third parties bear much of the cost (financially, clinically, and to some extent the costs of resistance), so neither the physician nor the patient feels the financial effects of their respective decisions. The direct costs of the therapy and the indirect costs of increased resistance are quite significant. ${ }^{98}$

Internalization by drug firms occurs on some scale as pharmaceutical firms grow larger and hold several antibiotics in their patent portfolios. Expanding the boundaries of the firm is not a likely solution to the waste problem unless we are willing to permit a single company to control most or all global patents for EPK. Imposing Pigovian taxes on drug firms for wasting EPK has apparently not been attempted. The path taken by the Statute of Gloucester also remains untrod, although the reversionary interest belongs to all humanity.

Internalization by consumers is also possible. If consumers faced a tax for misuse of EPK, then utilization of EPK would likely drop. Eric Kades, Professor of Law at William \& Mary Law School, champions this approach, which will be critiqued in Section III.A below.

Most of the response to EPK waste has focused on collective action. Medical societies, hospitals, nursing homes, and public health organizations issue guidelines encouraging rational antibiotic use. Health care payors develop formularies, ${ }^{99}$ academic detailing, ${ }^{100}$ and evidence-based medicine (EBM) guidelines ${ }^{101}$ to the same effect. Some governments have imposed

96. Victoria Stagg Elliott, FDA Approves First Ketolide Antibiotic, AMA News, Apr. 26, 2004.

97. Id.

98. The Infectious Diseases Society of America estimates the cost at "billions" and cites the Institute of Medicine estimate of "at least \$4 billion to $\$ 5$ billion annually." BAD Bugs, supra note 1, at 13; see also supra note 77.

99. Sandra L. Arnold, Interventions to Improve Antibiotic Prescribing, in Antibiotic Policies, supra note 4 , at 510-11, 515-16.

100. John Kasprak, West Virginia's Prescription Drug Academic Detailing Program, OfFICE OF Legis. Research (OLR) Research ReP., Jan. 5, 2005, at http://www.cga.ct.gov/2005/rpt/2005-R0050.htm.

101. Examples of EBM guidelines for rational antibiotic use include efforts by the Infectious Diseases Society of America (IDSA) and the British Thoracic Society (BTS). Dilip Nathwani, UK Guidelines: Methodology and Standards of Care, in AntiBiotic Policies, supra note 4, at 28-29. 
increasingly stringent marketing, labeling, and utilization restrictions on antibiotics and ARVs to delay the onset of resistance. ${ }^{102}$ These conservation (collective action) strategies will be discussed in more detail in Section II.D below.

\section{B. Inadequate Access}

The purpose of pharmaceutical appropriation is to reward innovation by allowing the patent holder to earn patent rents, ${ }^{103}$ which are extracted by establishing prices well above the marginal cost of production. Rent extraction is best accomplished in high-income populations among people who can afford expensive patented drugs. In low- and medium-income populations, financial access to these drugs is a critical issue. ${ }^{104}$ Patent domain EPK is exposed to distributional and therapeutic inequities: the negative externality of inadequate access. ${ }^{105}$ Public domain EPK is less subject to this problem because it is free from patent rent extraction, making the drug available as a generic.

Access is a serious issue. Many patented pharmaceuticals are available to high-income populations at prices that exceed the annual per capita health budgets of low- and middle-income countries. If off-patent medications are equally effective, then perhaps nothing is lost. But when older drugs are no longer effective ${ }^{106}$ and the patented drug is clearly the best therapy, denying access in order to support recovery of R\&D costs is cruel and unnecessary.

102. See Who, Rational Use of Medicines by Prescribers and Patients, EB115/40, $\uparrow 19$ (Dec. 16, 2004) [hereinafter Rational Use]; see also Ctrs. for Disease Control and Prevention, Campaign to Prevent Antimicrobial Resistance in Healthcare Settings, at www.cdc.gov/drugresistance/healthcare/ default.htm (last updated June 15, 2005); FDA, FDA Task Force on Microbial Resistance: Key RECOMMENDATIONS AND REPORT (Dec. 2000), available at http://www.fda.gov/oc/antimicrobial/ taskforce2000.html (last visited July 10, 2005).

103. I suffer the term patent rents, but the better term would be pharmaceutical appropriation rents, whether or not derived from patent law.

104. See Rational Use, supra note 102, \18; 't Hoen, supra note 34, at 1 (2005).

105. The term inadequate access shares some characteristics with deadweight loss, but emphasizes the distributional and consequential effects of rent extraction and the constrained production inherent in monopoly pricing. For example, in a standard account of deadweight loss, the deadweight loss might be small if the monopolist refuses to sell near the marginal cost of production to low-income populations, as the lostproduction was small. From theperspective of inadequate access, however, allowing several million people worldwide to die of AIDS without ARV treatment imposes a tremendous cost, whether or not they could ever have purchased ARVs at market prices.

106. Four of the top six deadly diseases in Africa have become increasingly resistant to first-line treatment. Madeline Drexler, Antimicrobial Resistance (AMR) in Africa: Smoldering in the Shadows, 20 APUA Newsl. No. 4 (Alliance for the Prudent Use of Antibiotics, Boston, Mass.), 2002, at 1. 
Cruel because people will die while a lifesaving treatment is possible; unnecessary because low-income populations would never have contributed much towards global R\&D cost recovery anyway. ${ }^{107}$ Denying AIDS drugs to Africa in order to support patent rent extraction is akin to genocide ${ }^{108}$ for the widow's mite. ${ }^{109}$

Access may also transpose the waste problem articulated above. While overuse of antibiotics may create a resistance problem in high-income countries, resistance may be driven more by subtherapeutic dosages due to poverty in low-income countries. ${ }^{110}$ Spotty access may accelerate resistance while a stable supply chain will have the opposite effect.

The human and economic costs of inadequate access are staggering, shattering the fragile economies of many countries and the lives of hundreds of millions of people. Estimates of the cost of this externality range in the tens of billions of dollars in high-income countries, ${ }^{111}$ and are much higher, as a percentage of GDP, in low- and medium-income countries. ${ }^{12}$

Some pharmaceutical companies have responded to the AIDS treatment crisis by establishing voluntary differential pricing regimes in certain low- and medium-income populations. While laudable, these programs are limited to particular diseases, drugs, or populations. Voluntary differential prices are not nearly low enough and are not generally priced at the lowest possible marginal

107. F.M. Scherer, A Note on Global Welfare in Pharmaceutical Patenting, 27 WorLd ECON. 1127, 1141 (2004) (proposing reduction of pharmaceutical appropriation in low-income countries); Kevin Outterson, Fair Followers: Expanding Access to Generic Pharmaceuticals for Low-Income Populations (Aug. 20, 2005), available at http://www.SSRN.com/abstract $=667323$ (last visited Sept. 10, 2005) [hereinafter Fair Followers].

108. $C f$. Lawrence Lessig, The International Information Society, 24 Loy. L.A. ENT. L. Rev. 33, 34-37 (2004).

109. Mark 12:41-44; Luke 21:2-4

110. Cf. Denis K. Byarugaba, Antimicrobial Resistance and its Containment in Developing Countries, in AntiBiotic Policies, supra note 4, at 618, 633-35 (noting that subtherapeutic dosages due to patent poverty or supply chain instability are likely to speed resistance).

111. Frank R. Lichtenberg, Are the Benefits of Newer Drugs Worth Their Cost? Evidence from the 1996 MEPS, 20 HeAlth AfF. 241, 241-51 (2001) (concluding that increased drug utilization in the U.S. would save billions of dollars, one possible measure of the negative externality of inadequate access in the U.S.).

112. The global cost of inadequate access to health is certainly many hundreds of billions of dollars per year. WhO, Comm'n on Macroeconomics and Health, Macroeconomics and Health: Investing in Health For Economic Development 103-08 (2001) (calculating the positive economic benefits of improved health access in developing countries as $\$ 360$ billion per year between 2015 and 2020) [hereinafter WhO, Comm'n on Macroeconomics and Health]. Some portion of that cost could be apportioned to inadequate access to patented pharmaceuticals. Evidence from the AIDS treatment crisis globally suggests the amount would be significant. See Pharmaceutical Arbitrage, supra note 13, at 251-55; 't Hoen, supra note 28, at 29-30. 
cost. ${ }^{113}$ Even at the lowest marginal cost, a lifesaving drug regime offered at the marginal cost of production might still be out of reach from the perspective of a low-income patient. An annual supply of the highly effective anti-AIDS FDC drug Triomune at $\$ 240$ per year may still be too expensive in Malawi. ${ }^{114}$ Such patients are unable to afford the therapy due to extreme poverty and require a Pigovian subsidy.

The patent rent extractor (such as GlaxoSmithKline) has no economic incentive to engage in widespread marginal cost pricing for the world's lowand medium-income populations. Establishing a few programs might bolster public relations, but pharmaceutical companies have no internalized economic incentive to systematically address inadequate access. In some cases, companies refuse to participate in these access programs. In 2004, Bayer successfully lobbied Canada to exclude Bayer's antibiotic Avelox/vigamox (moxifloxacin $)^{115}$ from the World Trade Organization (WTO) Doha process for export to low-income countries. ${ }^{116}$ Avelox treats pneumonia, a major cause of death worldwide. Avelox was excluded despite the fact that it had many years of patent life remaining ${ }^{117}$ and that sales of licensed Avelox outside of the Organization for Economic Co-operation and Development (OECD) are very modest. Total sales of licensed Avelox in Latin America in 2004 were $\$ 4,000 .^{118}$

If Pigovian taxes were imposed on drug firms to help them internalize the cost of inadequate access, the amount would be in the order of tens of billions of dollars per year. ${ }^{119}$ The Commission on Macroeconomics and Health called for additional global donor investments in health within this range. ${ }^{120}$ If

113. Fair Followers, supra note 107, § 5.2.

114. See discussion infra section II.D.2 (concerning Triomune).

115. Bayer uses two brand names for moxifloxacin: Avelox in tablet and injectable forms and Vigamox in opthalmic drops.

116. See 't Hoen, supra note 34 , at 5.

117. The FDAORANGE Book lists three patents for moxifloxacin, with expirations on June 30, 2009, March 4, 2014, and December 5, 2016. FDA ORANGE Book, supra note 24.

118. IMS data reports that for the annual period ending October 2004, U.S. sales of Avelox were $\$ 231$ million, while Latin American sales were only $\$ 4,000$. No sales were reported by IMS in French West Africa. See IMS Database, supra note 76. Bayer would not have lost much revenue if it had agreed to place Avelox on the Canadian list.

119. The global cost of inadequate access to health is certainly many hundreds of billions of dollars per year. WHO, COMM'N ON MACROECONOMICS AND HEALTH, supra note 112, at 103-08 (calculating the positive economic benefits of improved health access in developing countries as $\$ 360$ billion per year in 2015 to 2020). Some portion of that cost could be apportioned to inadequate access to patented pharmaceuticals. Evidence from the AIDS treatment crisis globally suggests the amount would be significant. Pharmaceutical Arbitrage, supra note 13, at 251-55.

120. WHO, COMm'N ON MACROECONOMiCS AND Health, supra note 112, at 11 (stating that donors 
indeed the inadequate access negative externality ranges in the tens of billions of dollars per year, then the Pigovian tax would need to be equally significant and would prompt dramatic global action. This Pigovian tax should be imposed to the extent that pharmaceutical companies do not participate in effective programs to provide access to medicines. A Pigovian tax of this magnitude and purpose would be a radical move for global public health. Alternatively, this externality may be addressed through compulsory licensing and mandatory differential pricing programs to ensure therapeutic access. ${ }^{121}$

\section{Balancing Consumer Surplus, Access, and Innovation}

Lifesaving drugs greatly benefit society. To the extent that pharmaceutical companies do not capture all consumer surplus created by antibiotic therapies, the public enjoys a positive externality of consumer surplus: better health at a bargain price. The public also benefits when treated individuals are less likely to transmit infection to others, an epidemiological effect. Frank Lichtenberg has estimated the unappropriated consumer surplus for patented drugs in the United States to be in the range of tens of billions of dollars or more per year. ${ }^{122}$

Research and development is quite possibly another positive externality. ${ }^{123}$ The firm that invests in R\&D may reap appropriated rewards through the patent system, but is unlikely to capture all of the societal benefits. Nor should it; complete appropriation would exacerbate the access and anticommons (congestion) effects of IP rights. ${ }^{124}$

Unappropriated consumer surplus creates a potential drag on innovation. If all of the consumer surplus could be captured by drug companies through perfect price discrimination, then additional funds would be available for R\&D. Put another way, encouraging drug companies to raise prices shifts funds from consumer surplus to drug company operating margins. Allowing drug companies to capture an additional dollar of consumer surplus might result in 8 to 33 cents of additional R\&D expenditures. ${ }^{125}$ Conversely,

should commit an additional $\$ 35$ billion per year by 2007 for all global health needs).

121. For an extended discussion of these issues, see Pharmaceutical Arbitrage, supra note 13, at $223-30$.

122. See Lichtenberg, supra note 111

123. If $R \& D$ expenditures are already socially supra-optimal, then marginal $R \& D$ generates negative externalities. Pharmaceutical Arbitrage, supra note 13, at 220.

124. William M. Landes \& Richard A. Posner, The Economic Structure of Intellectual Property LAW 13-14 (2003) (congestion); Heller \& Eisenberg, supra note 21, at 698 (anti-commons).

125. Donald W. Light, In the Name of Research: Raising Drug Prices Here and Abroad, Presentation 
improving access through price controls may well reduce $R \& D$ expenditures, ${ }^{126}$ although this effect has not been verified empirically. ${ }^{127}$

Policymakers commonly assume that increasing biomedical R\&D expenditures is an unalloyed public good. ${ }^{128}$ However, we should not assume that increasing $R \& D$ expenditures at the cost of consumer surplus or access is socially beneficial. R\&D policy must consider both the costs and the benefits of an incremental unit of R\&D. The public policy goal should be to achieve the socially optimal amount of biomedical R\&D, rather than maximizing $R \& D$ at all costs.

We have several reasons to be skeptical of the IP maximalist agenda. Taken to its extreme, maximizing IP would condemn generic drug entry altogether, making pharmaceutical patents perpetual. ${ }^{129}$ However, additional R\&D expenditures may offer declining marginal returns, at least in "normal" science. ${ }^{130}$ If global EPK is finite like fossil fuels, then additional resources for EPK drug discovery may be wasted and could be better spent on conservation and other research targets. ${ }^{131}$ In any case, society's expenditures for drug R\&D may already be supra-optimal and resources could be directed

at the David Rogers Health Policy Colloquium, Cornell University Medical College (Dec. 15, 2004) (low estimate) (slides on file with author); John A. Vernon, Examining the Links between Price Regulation, Importation and Firm Investment in Pharmaceutical R\&D, Presentation at the University of Connecticut International Law Review Symposium (2004) (high estimate) (slides on file with author).

126. Trade Admin., U.S. Dep't of Commerce, Pharmaceutical Price Controls in OeCD Countries: Implications for U.S. Consumers, Pricing, Research and Development, and InNOVATION 25-31 (Dec. 2004). This report was the subject of a hearing in the U.S. Senate Committee on Health, Education, Labor, \& Pensions on February 17, 2005. Four of the persons testifying were selected by the Republican leadership and were favorable towards the Report. For the sole dissenting voice, see Drug Importation: Would the Price Be Right?: Hearing Before the Comm. on Health, Educ., Labor, \& Pensions, 109th Cong. (2005) (statement of Kevin Outterson, Assoc. Professor of Law, West Virginia Univ.), available at http://www.help.senate.gov/testimony/t199_tes.html (last visited July 10, 2005).

127. See Outterson, Statement Drug Importation, supra note 126.

128. Senator Enzi typified this approach at the U.S. Senate Health, Education, Labor, and Pensions Committee Hearing on Drug Importation. See, e.g., Press Release, Senator Michael Enzi (R-WY), Rapid Advances, in Science, Drug Development, Demand Change to FDA's Review Process, Enzi says (Mar. 3, 2005), available at $\mathrm{http} / / \mathrm{www} . s e n a t e . g o v / \mathrm{member} / \mathrm{wy} / \mathrm{enzi} / \mathrm{general} / \mathrm{helpfdahear} 1 . \mathrm{htm}$.

129. Consumer surplus expands following patent expiration if prices fall. Thus the process of generic entry (and the Hatch-Waxman compromise generally) is inconsistent with an IP maximalist approach.

130. Thomas S. Kuhn, The Structure of Scientific Revolutions 10 (2d ed. 1986). Large pharmaceutical companies operate primarily in normal science; small biotechnology firms and academic researchers are more likely to pursue new research paradigms. Adjusting the systems to encourage more breakthrough research will have to be saved for another day, but for an interesting thesis, see Peter Lee, Note, Patents, Paradigm Shifts, and Progress in Biomedical Science, 114 YALE L.J. 659, 662-63 (2004) (describing how patents raise costs in normal science, encouraging revolutionary science).

131. See infra Section I.B (last 2 paragraphs). 
elsewhere. ${ }^{132}$ Finally, the inefficiency of the additional incentive is great. At best, only a third of the captured consumer surplus might result in R\&D expenditures. Proposals to maximize biomedical R\&D by strengthening IP rights should be scrutinized as possible industry rent-seeking rather than sound public policy. ${ }^{133}$ Other alternatives such as R\&D prizes, ${ }^{134}$ patent buyouts, ${ }^{135}$ and treaty-based frameworks ${ }^{136}$ might be more efficient while avoiding the aforementioned access problems. ${ }^{137}$

One prominent proposal along these lines is the Medical R\&D Treaty, ${ }^{138}$ which does not rely on retail sales to accomplish R\&D cost recovery. The market for innovation is separated from the market for drugs. Instead, each country's contributions to global pharmaceutical R\&D are compared against an agreed norm. Free riders will pay a tax. Those countries carrying more than their fair share will receive a subsidy.

The Medical R\&D Treaty not only resolves the free rider issue, but also the negative externality of inadequate access. When R\&D cost recovery is decoupled from retail sales, sales to consumers will be made at the marginal cost of production without affecting innovation. The incentive to counterfeit pharmaceuticals also diminishes greatly under this approach. ${ }^{139}$

132. Pharmacentical Arbitrage, supra note 13, at 220-22; Uwe E. Reinhardt, An Information Infrastructure for the Pharmaceutical Market, 23 HeALth AFF. 107, 111-12 (2004).

133. Andrew Farlow, The Cost of R\&D: How Much Money Is Needed to Address the Current Need?, Presentation to the Int'l Conference on Ensuring Innovation for Neglected Diseases (June 8, 2005),

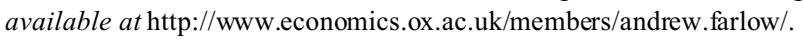

134. Michael Kremer, Creating Markets for New Vaccines: Part I: Rationale \& Part II: Design Issues, in 1 InNovation Policy AND THE ECONOMY 35-109 (Adam B. Jaffe et al. eds., 2001) [hereinafter Kremer, Creating Markets].

135. See Mattias Ganslandt et al., Developing and Distributing Essential Medicines to Poor Countries: The DEFEND Proposal, 24 WorLd ECON. 779, 788 (2001).

136. Tim Hubbard, Alternatives to the Price System, Presentation at Columbia University (Dec. 4, 2003), at http://www.earthinstitute.columbia.edu/cgsd/documents/hubbard.ppt (last visited July 10, 2005); James Love, A New Trade Framework for Global Healthcare R\&D, Presentation at Columbia University (Dec. 4, 2003), at http://www.earthinstitute.columbia.edu/cgsd/documents/love_000.pdf (last visited July 10, 2005).

137. See Dean Baker \& Noriko Chatani, Promoting Goods Ideas on Drugs: Are Patents the Best Way? The Relative Efficiency of Patent and Public Support for Bio-Medical Research (CEPR Research Report, Oct. 11, 2002), available at www.cepr.org.; James Love, From TRIPS to RIPS: A Better Trade Framework to Support Innovation in Medical Technologies (Workshop on Economic Issues Related to Access to HIV/AIDS Care in Developing Countries, Université de la Méditerranée, Marseille, France, May 27, 2003); Aidan Hollis, An Efficient Reward System for Pharmaceutical Innovation (draft dated Jan. 17, 2005), available at $\mathrm{http}: / /$ econ.ucalgary.ca/hollis.htm.

138. Hubbard, supra note 136; Love, supra note 136.

139. Kevin Outterson, Resolving Dysfunctional Pharmaceutical Arbitrage and Counterf eit Drugs Through The Proposed Pharmaceutical R\&D Treaty (submission to the WHO Comm'n on Intellectual Prop. Rights, Innovation \& Pub. Health, Nov. 13, 2004), available at http://www. 
A broadly similar but more limited approach is patent buyouts for the public domain, by which a donor government or foundation purchases the patent to a drug and donates it to the public domain or holds it for public use. ${ }^{140}$ Paying market value for the patent protects innovation. Entering the public domain resolves access issues by removing patent rent extraction and enabling marginal cost production by generic companies.

Another coordination approach creates prizes for pharmaceutical innovation. ${ }^{141}$ Professor Kremer's prize proposals are focused more particularly on neglected diseases. Prizes may offer rewards for intermediate steps short of a patent and may utilize a product purchase commitment rather than a patent buyout. Kremer's proposals primarily address inadequate incentives to undertake particular types of $\mathrm{R} \& \mathrm{D}$, but they can also function to coordinate free riding and promote access.

Each of these coordination mechanisms focus on the supply side of the EPK problem. ${ }^{142}$ We now turn to the demand side, conserving EPK for its highest and best uses.

\section{Conserving EPK in the Public and Patent Domains}

As legal support for appropriation falls away over time, EPK loses the characteristic of appropriability and gradually passes into the public domain. Indeed, this was the intent of the disclosure aspect of the patent bargain. Public domain EPK is rivalrous and exposed to common pool resource problems. The need to manage EPK was quickly recognized by Professor Alexander Fleming as early as $1946 .{ }^{143}$

The size and scope of this conservation problem is an inverse function of waste: To the extent that EPK has been wasted during the patent domain, less will be exposed to common pool rivalry. On the other hand, if patent domain

who.int/intellectualproperty/submissions/en/pharma_arbitrage.pdf (last visited July 10, 2005).

140. Fair Followers, supra note 107, § 5.3. In a hybrid approach, the patent could be bought out and donated to the public domain only for non-OECD countries at a much reduced price. The rich OECD countries would be left with the current patent-based system. This hybrid addresses most of the access issues globally, allowing marginal cost production for most of the world, while not disturbing $90 \%$ or more of the profits of pharmaceutical companies.

141. Kremer, Creating Markets, supra note 134, at 35-36.

142. Innovation and access are supply issues, as opposed to management and conservation of demand.

143. See Ian Phillips, Antibiotic Policies-A Historical Perspective, in Antibiotic Policies, supra note 4, at 1-4 (noting that hospitals were quick to implement programs to constrain resistance and citing Sir Alexander Fleming, History and Development of Penicillin, in Penicillin, Its Practical ApPlication 1-23 (Sir Alexander Fleming ed., 1946)). 
waste has been minimized due to careful conservation, ${ }^{144}$ the value of the public domain resource increases. Success in one domain increases the stakes and the need to protectEPK in the other. The following sections discuss some of the salient features of EPK conservation.

\section{Global EPK Conservation}

Conservation of EPK may require global coordination between many states in a globalized world. ${ }^{145}$ States which carefully manage antibiotic use incur all of the program and clinical costs; however, some of the benefits are global, a positive externality for which the State is not compensated. Conversely, a State that is unable or unwilling to implement strict conservation regimes ${ }^{146}$ may export antibiotic resistance to its neighbors and the globe without bearing the full weight of the consequences. ${ }^{147}$ This is the conservation problem of globalization, suggesting that EPK should be managed at the global level, much as the Agreement on Trade-Related Aspects of Intellectual Property Rights (TRIPS) established a global floor for IP appropriation. ${ }^{148}$ The WHO has taken several steps to encourage EPK conservation. ${ }^{149}$ The European Antibiotic Policy calls for subsidizing efforts in low-income countries to reduce resistance. ${ }^{150}$

The global dimension of EPK may be overstated. The popular press abounds in stories about potential global pandemics such as SARS. One

144. The research on which conservation techniques are most effective is quite unsatisfactory. In a major review of all published studies, no clear conclusions could be reached on the best conservation strategies, or even whether any strategy was effective in combating resistance in the community. Arnold, supra note 99 , at 518-19.

145. Richard D. Smith \& Joanna Coast, Antimicrobial Resistance: A Global Response, 80 BuLL. OF THE WHO 126 (2002).

146. For a discussion of the implementation of antibiotic policies in developing countries, see Anibal Sosa, Antibiotic Policies in Developing Countries, in Ant IBIotic Policies, supra note 4, at 602-04. Given the lack of pharmacy infrastructure in many countries, effective surveillance and control of antibiotic prescribing is difficult. $I d$. at $606-11$.

147. In both examples, some of the costs and benefits are internalized locally. While antibiotic resistance does spread geographically, resistance may vary dramatically between different regions and institutions. At least some of this variance is attributed to local conservation decisions. LEvy, supra note 1 , at $152,157-58,301-02$.

148. TRIPS is a move towards global standardization of IP law. Countries retain some flexibility, but in practice this flexibility is frequently waived, particularly by poorer countries. THORPE, supra note 66 , at 1 .

149. See, e.g., Rational Use, supra note 102.

150. E. Keuleyan \& I.M. Gould, European Study Group on Antibiotic Policy (ESGAP), Key Issues in Developing Antibiotic Policies: From an Institutional Level to Europe-Wide, 7 CLINICAL Microbiology \& InfECtion 16-21 (Supp. 6, 2001). 
might infer from these discussions that resistance spreads uniformly and internationally. While disease certainly moves around the globe, we should not over-emphasize the global movement of resistance. Resistance retains significant individual, local, and regional variances. ${ }^{151}$ These variances may result from environmental differences, conservation strategies, or exogenous factors like the frequency of indwelling lines as vectors for infection. Resistance is most prevalent in emerging upper middle-income countries. ${ }^{152}$ Resistance may also arise multifocally, developing more or less independently in multiple settings. ${ }^{153}$ Negative externalities may be entirely local (within a hospital ICU) ${ }^{154}$ or regional (within a community), rather than global. To the extent that any of these conditions hold true, coordination can be partially successful at the local, regional and domestic levels, even absent effective global coordination. In December 2004, the WHO reported that most countries still fail to utilize effective conservation tools at the domestic and local levels, ${ }^{155}$ so much work remains to be done. Nevertheless, many aspects of EPK are global public goods requiring global coordination for best results. ${ }^{156}$

\section{Conservation Within Therapeutic Classes}

The biology of resistance pays no attention to the patent doctrines of scope or inventive step, ${ }^{157}$ but these doctrines may affect EPK biology.

151. Livermore, supra note 4, at s15-16; Werner, supra note 48, at 515 ("We found large differences in resistance rates, even in neighboring countries. A variety of factors are responsible....”); see also James A. Karlowsky et al., Factors Associated with Relative Rates of Antimicrobial Resistance Among Streptococcus pneumoniae in the United States: Results from the TRUST Surveillance Program (1998-2002), 36 CLiniCAL INFEC TiOus Diseases 966-68 (2003) (noting statistically significant regional variations in resistance to penicillin, azithromycin, TMP-SMX, and ceftriaxone across the United States); Emilio Pérez-Trallero et al., Geographical and Ecological Analysis of Resistance, Coresistance, and Coupled Resistance to Antimicrobials in Respiratory Pathogenic Bacteria in Spain, 49 ANTIMICROBIAL AgENTS \& CHEMOtheRAPy 1965-72 (2005) ("We highlight the importance of differential geographical frequencies of coresistance... and coupled resistance ... probably resulting from different local coselective events.").

152. Society's success in treating other conditions results in an increased population with compromised immune systems more prone to opportunistic infections.

153. Livermore, supra note 4, at s12-13.

154. See, e.g., O. Leroy et al., Hospital-Acquired Pneumonia in Critically Ill Patients: Factors Associated With Episodes Due to Imipenem-Resistant Organisms, 33 J. Infection 129, 129-35 (June 2005) (suggesting factors to control hospital-acquired infection of resistant microbes).

155. Rational Use, supra note 102, 99.

156. Smith \& Coast, supra note 145 , at 127-30.

157. The same might be said of our students. 
Resistance may develop against a particular mode of action rather than to a specific patented molecule. ${ }^{158}$ This biological reality creates negative externalities and coordination problems between drugs which share a common mode of action, that is, within therapeutic classes. ${ }^{159}$ A major example of cross-resistance within a therapeutic class is the Non-Nucleoside Reverse Transcriptase Inhibitor (NNRTI) class of ARVs for AIDS. ${ }^{160}$

Drug companies introducing a new antibiotic class face strong incentives to maximize sales of the new class, ${ }^{161}$ to the detriment of subsequent drugs in the class. Unconstrained appropriation will be fleeting and certainly much shorter than the patent period. ${ }^{162}$ The first mover also benefits if the prior classes have become ineffective. ${ }^{163}$ The best medical conservation for global public health may well require the opposite tactic: prolong the usefulness of the older classes, while holding the new class off the market, in reserve. Joint coordination amongst patent owners within a class might conceivably address this issue, given a waiver from competition laws. This waiver would necessarily permit rival firms within a class to jointly control both supply and price.

158. Examples of the development of cross-resistance within a therapeutic class include fluoroquinolones. Jerome J. Schentag \& Alan Forrest, Roles for Pharmacokinetics and Pharmacodynamics, in The Resistance Phenomenon in Microbes and Infectious Disease Vectors: Implicationsfor Human HeAlth AND StrategieS For Containment 181 (Stacey L. Knobleret al. eds., 2003).

159. Therapeutic classes generally mean the categories by which pharmaceuticals are grouped, generally based upon the structure of the molecule, the therapeutic target, or the mode of action. For example, antibiotics are classed based upon whether their mode of action is DNA inhibition, RNA inhibition, cell wall, or protein synthesis. In lipid-lowering medications, statins have a similar mode of action. In NSAIDS, the Cox-2 inhibitors such as Celebrex or Vioxx share a mode of action. Within a particular class, many drugs may reach the market, very frequently with different patent holders. For a discussion of the economics of follow-on innovation within drug classes (the so-called "me too" drugs), see generally Joseph DiMasi \& Cherie Paquette, The Economics of Follow-On Drug Research and Development: Trends in Entry Rates and Timing of Development (Submission to the WhO Comm'n on Intellectual Prop. Rights, Innovation \& Pub. Health, Dec. 2, 2004), available at http://www. who.int/intellectualproperty/submissions/Submission_DiMasi.pdf (last visited July 10, 2005).

160. See, e.g., Clotet, supra note 33, at 123-30 ("Resistance to one drug often result[s] in crossresistance to many, if not all, others in the same [ARV] class."); V. Joly, D. Descamps \& P. Yeni, NNRTI Plus PI Combinations in the Perspective of Nucleoside-Sparing or Nucleoside-Failing Antiretroviral Regimes, 4 AIDS Rev. 128-39 (July-Sept. 2002) (describing the large degree of cross-resistance within the 3 available NNRTI drugs); see also Mocroft et al., supra note 33, at 201-09 ("The roles of cross-resistance and adherence in response to second-line regimens needs further investigation.”).

161. See supra Section II.A (waste).

162. The average time before a second member of a therapeutic class is marketed is about 1.2 years. DiMASI \& PAQUETTE, supra note 159 , at 5.

163. Joint ownership across classes would address this problem but would require a single firm to own all members of both classes. 
A further complication arises when one or more drugs in a therapeutic class are off-patent. Once the first member of a class enters the public domain, all remaining owners are exposed to enhanced common pool rivalry and are thereby tempted to waste. This remains true even if other drugs in the class retain many years of patent protection. With one or more drugs in the public domain, private coordination cannot work, for there is no barrier to entry by a non-conforming and profit-maximizing generic producer. Public conservation is required when a vulnerable class of EPK simultaneously resides in both public and patent domains. ${ }^{164}$ Class resistance also weakens future members of the class still in the drug development pipeline, ${ }^{165}$ extending the problem back to the private domain.

A patent-based approach to these issues might grant a very broad patent right for the entire drug class to the first applicant. The first to patent a new target or mode of action would control the licensing of downstream innovation, and thus manage the class. A single firm would control all EPK within a therapeutic class and generic entry would be forbidden.

\section{Conservation Between Therapeutic Classes}

Class-based resistance problems are further magnified when some resistance traits are transmitted across classes. For example, prolonged use of a single antibiotic has stimulated the emergence of antibiotics-resistant bacteria from different classes that were not used in treatment. This effect has been observed in the widely-used ciprofloxacin. ${ }^{166}$ In another experiment, resistance crossed three classes with prolonged use of a single drug. ${ }^{167}$ In Iceland, use of macrolides and co-trimoxazoles selected for penicillin resistance more aggressively than penicillin itself by a factor of three or four. ${ }^{168}$ Cross-class resistance appears between some classes (ß-lactams,

164. While class patents would resolve common pool rivalry amongst private parties, it would not address waste as the class patent approached expiration. In any case, public conservation would be necessary once the EPK entered the public domain.

165. LEVY, supra note 1, at 221-23.

166. "Even more surprising, the resistances were not limited to naturally occurring antibiotics, but also to the newer synthetic antimicrobials, the fluoroquinolones, such as norfloxacin and ciprofloxacin." Id. at 110-11, 219-20.

167. In one experiment, feeding oxytetracycline to chickens led to the appearance of $E$. coli "with resistance not only to tetracycline, but also to ampicillin, streptomycin, and sulfonamides, even though the chickens had never been fed these drugs." Id. at 163.

168. Ian M. Gould, Antibiotic Use-Ecological Issues and Required Actions, in ANTIBIotic Policies, supra note 4, at 705 (citing Karl G. Kristinsson, Modification of Prescribers' Behavior: The Icelandic Approach, 5 Clinical Microbiology \& Infection 4S43, 4S43-47 (1999)). 
macrolides, and TMP-SMX), but nonfluoroquinolone use does not apparently create cross-resistance among Streptococcus pneumoniae with levofloxacin (an oral fluoroquinolone). ${ }^{169}$ Exposure of Pseudomonas aeruginosa to antibiotics from two different classes created cross-class resistance in one direction but not in the other. ${ }^{170}$ If transmission of resistance across classes is significant, then all susceptible classes might require joint coordination or conservation. If private ordering remained the mechanism of coordination, patent scope or waivers of antitrust law would have to expand greatly. At some point, the effort becomes a government-supported antibiotic cartel rather than a free market.

A related effect occurs when patents for the components of a combination therapy are held by different companies. Fixed-Dose Combination (FDC) drugs for HIV combine multiple classes of drugs in a single pill. FDCs improve patient compliance and may delay resistance. ${ }^{171}$ Triomune is Cipla's brand name for a very important triple-drug therapy FDC for sub-Saharan Africa, containing nevirapine (NVP), stavudine (d4T), and lamivudine (3TC). ${ }^{172}$ Triomune is produced as an unlicensed generic and sold for sixtyseven cents per day or US\$244 per year. ${ }^{173}$ As of June 2005, Triomune was not available in a licensed FDC form, a rare inversion in which a generic

169. Karlowsky et al., supra note 151 , at 969.

170. The antibiotics were ciprofloxacin (a fluoroquinolone) and cefepime (a cephalosporin). Exposure to only ciprofloxacin resulted in resistance to both drugs; exposure to only cefepime selected for cefepime resistance, but did not result in ciprofloxacin resistance in this organism. S.A. Alyaseen et al., Selection of Cross-Resistance Following Exposure of Pseudomonas aeruginosa Clinical Isolates to Ciprofloxacin or Cefepime, 49 Antimicrobial Agents \& Chemotherapy 2543, 2543-45 (2005).

171. See, e.g., Christian Laurent et al., Effectiveness and Safety of a Generic Fixed-Dose Combination of Nevirapine, Stavudine, and Lamivudine in HIV-1-Infected Adults in Cameroon: OpenLabel Multicentre Trial, 364 The LANCEt 29, 29-34(July 3, 2004); Gregory K. Robbins et al., Comparison of Sequential Three-Drug Regimens as Initial Therapy for HIV-1 Infection, 349 NEw EnG. J. MEd. 2293 (Dec. 11, 2003); Robert W. Shafer et al., Comparison of Four-Drug Regimens and Pairs of Sequential Three-Drug Regimens as Initial Therapy for HIV-1 Infection, 349 New ENG. J. MeD. 2304 (Dec. 11, 2003). The U.S. government agrees. See U.S. Dep't of Health and Human Services, Joint Statement Issued Regarding Principles for Fixed-Dose Combination Drug Products (Apr. 8, 2004), available at http://www.hhs.gov/news/press/2004pres/20040408b.html (last visited July 8, 2005). Different combinations of ARVs should be available in order to minimize resistance. Joly, Descamps \& Yeni, supra note 160 , at 128 ("Such combinations should not be used in patients infected with HIV-1 group O or HIV-2, due to the natural resistance to NNRTI of these subtypes."). This also underscores the need for genotyping diagnostics on the patient prior to initiation of HAART. Clotet, supra note 33, at 123-30. For an economic model of FDC resistance, see Ramanan Laxminarayan \& Martin L. Weitzman, Value of Treatment Heterogeneity for Infectious Diseases, in Battling Resistance, supra note 29, at 63, 66.

172. Pharmaceutical Arbitrage, supra note 13, at 250.

173. MSF, Untangling the Web of Price Reductions, supra note 35, at 15. 
company is a sole-source supplier. ${ }^{174}$ The patents for nevirapine, stavudine, and lamivudine are held by different companies, ${ }^{175}$ and they are apparently unable to conclude a cross-licensing agreement. FDCs are important in other therapeutic areas as well. Combination drugs in Directly-Observed Treatment, Short-course (DOTS) represent the current best practice for treatment of resistant strains of tuberculosis, and FDC anti-malarial drugs (specifically, Fixed-Dose Artesunate Combination Therapy, or FACT) are currently the best first-line and prophylactic treatments. ${ }^{176}$ While some ARVs demonstrate strong susceptibility to cross-resistance within a class, ${ }^{177}$ resistance between classes appears to be less of a problem. ${ }^{178}$

Private ordering requires all patents in a FDC to be held by a single firm (as it is with Novartis's anti-malarial drug Coartem (Artemether/ lamefantrine)), but economic models predict that optimal FACT therapy will require partial subsidies of multiple combination drugs, using an artemisinin companion from different classes. ${ }^{179}$ Coordination of these subsidies amongst all FACTs is indicated, but it is not at all clear how extended patent terms would facilitate that process. Single firm ownership is unlikely for FDCs for AIDS, with key patents spread amongst several companies. Private firms might cross-license to permit FDC production. However, the failure over many years to cross-license patented ARVs, in the face of the most pressing

174. 't Hoen, supra note 34, at 2 (recommending FDCs blocked by patents); UNICEF-UNAIDSWHO-MSF, Sources and Prices of Selected Medicines and Diagnostics for People Living with HIV/AIDS 11 (2003) (NVP + D4T + 3TC fixed-dose combination not available in the U.S.), available at http://www.who.int/medicines/organization/parl/ipc/sources-prices.pdf (last visited July 10, 2005).

175. FDA ORANGE BooK, supra note 24.

176. WHO, Access to Arte misinin-Based Combination Antimalarial Drugs of Acceptable QuAlity (2d ed. Apr. 26, 2004), available at http://mednet3.who.int/prequal/mal/mal.supplies/pdf (last visited July 10,2005). The Artemether/lumefantrine FDC is manufactured by Novartis. For a description of the effort to create FDCs for malaria in Africa and Latin America, see Press Release, Drugs for Neglected Diseases Initiative (DNDI), Malaria Patients Enter DNDi Clinical Trials (July 2, 2004), at http://www. dndi.org/ (last visited July 10, 2005), and DNDi, "FACT" Sheet, at http://www.dndi.org/ (last visited July 18, 2005). FACT therapy is also important for delaying the emergence of an artemisinin-resistant mutation of Plasmodium falciparum. A single mutation could render the malaria parasite no longer susceptible to artemisinin. A.C. Uhlemann et al., A Single Amino Acid Residue Can Determine the Sensitivity of SERCAs to Artemisinins, 12 Nature Structural \& Molecular Biology 628-29 (2005). For an economic analysis, see Ramanan Laxminarayan, Mead Over \& David L. Smith, Will a Global Subsidy of Artemisinin-Based Combination Treatment (ACT) for Malaria Delay the Emergence of Resistance and Save Lives? (World Bank Policy Research, Working Paper No. 3670, 2005) [hereinafter Malaria Resistance].

177. See supra note 160 and accompanying text.

178. Roge et al., supra note 33, at 38-47 (noting that second-line treatment worked despite the presence of primary resistance mutations).

179. Malaria Resistance, supra note 176 , at 9-14. 
global catastrophe, ${ }^{180}$ suggests that transaction costs are much higher than Coase would have hoped. ${ }^{181}$ If private ordering is insufficient, public action will be required.

\section{Conservation and Market Entry}

New antibiotics enter the U.S. market after FDA approval. With the patent clock ticking, ${ }^{182}$ companies have every incentive to speed along the approval process. Once approved for marketing, the remaining patent period is adjusted per the Hatch-Waxman Act, ${ }^{183}$ and the company begins sales and marketing. Most firms prepare assiduously for marketing approval and hit the ground running as soon as possible. For innovative products which are safe and effective, speedy marketing is clearly in the public interest. ${ }^{184}$

But for some EPK, immediate marketing of the drug may not be in the social interest. Perhaps it should be saved for later or offered only in narrowly defined circumstances. ${ }^{185}$ EPK is unique in that the public may not benefit from the speedy uptake of an innovative, safe, and effective drug. When the first novel antibiotic in many years, Zyvox/linezolid, was introduced in April 2000 , sales skyrocketed to over $\$ 345$ million per year in the U.S., with significant sales across the globe as well. ${ }^{186}$ Social welfare might have called for a delayed introduction of Zyvox/linezolid, or for a less effective marketing campaign. This Article has already explored similar issues with

180. 't Hoen, supra note 34, at 2.

181. Coase famously postulated that if transaction costs were zero, then externalities could be resolved without regard to whom liability fell. With zero transaction costs, if the failure to produce a FDC created a negative externality, then an efficient license agreement would be concluded to address the externality. See generally Ronald H. Coase, The Problem of Social Cost, 3 J.L. \& Econ. 1-44 (1960).

182. The Hatch-Waxman Act restores some, but not all, of the lost patent time due to the FDA approval process. See 35 U.S.C. $\S \S 155,155 A, 156$ (2000). One suggestion being floated by PhRMA is to restore all of the FDA approval time for antibiotics. David M. Cocchetto, Regulatory and Other Incentives for Antibiotic Development, Presentation at the Center for Drug Evaluation and Research, IDSA/PhRMA/FDA Working Group Meeting 2, 4, 6, 17 (Nov. 19-20, 2002), available at www.fda.gov/ cder/present/idsaphrma/default.htm (last visited Dec. 8, 2004) [hereinafter PhRMA Working Group].

183. Drug Price Competition and Patent Law Restoration Act of 1984, Pub. L. No. 98-417, 98 Stat. 1585 (codified as amended in scattered sections of 15, 21, 28, and 35 U.S.C.) [hereinafter Hatch-Waxman Act].

184. If one assumes the National Drug Regulatory Authority has correctly found safety and efficacy, generally speedy marketing is desired by all parties. Public and private objectives frequently diverge during the drug approval process on these issues of safety and efficacy.

185. See infra Section II.D.6.

186. IMS Database, supra note 76. 
Tygacil/tigecycline, Zithromax/azithromycin, dalbavancin, and Ketek/telithromycin. ${ }^{187}$

\section{Conservation and Innovation}

Public regulation creates a tension with innovation. When market entry is delayed, or drug use managed to reduce demand, antibiotic sales are depressed. ${ }^{188}$ Absent other adjustments, conservation during the patent domain weakens appropriation and, thus, the financial incentive to innovate.

After patent expiration, this particular problem disappears, but is replaced by another innovation problem. Effective conservation of public domain EPK dampens the need for new antibiotics by keeping the old ones useful. Public conservation of EPK creates static gains (maximizing the usefulness of today's drugs), but presents apparent dynamic losses (future drug innovation is hindered). In reality, these innovation losses may not account for much because these new drugs were not needed yet. In this scenario, the older drugs are still effective. Postponing discovery of new antibiotics might be the best course so long as the present drugs are better managed. This is especially true if global EPK is a finite resource, as described in Section I.B above.

\section{Biological Complexity May Require Divergent Conservation Models}

Simple models of antibiotic innovation are challenged by biological complexity. Microbes develop resistance in many ways with significantly different biological expressions. ${ }^{189}$ As a result, diverse arrays of conservation responses are required, ${ }^{190}$ including some that work at cross purposes.

Some microbes are best managed with a sequence of drugs: exhausting one antibiotic at a time, whilst holding all others in reserve. For others, FDC therapy might be better suited. ${ }^{191}$ For some antibiotics, exhaustion is

187. See supra notes $78-97$ and accompanying text.

188. Many have made this observation. For a recent discussion, see Paul H. Rubin, The FDA's Antibiotic Resistance, 27 REG. 34-37 (2004).

189. Gould, supra note 168, at 704-08; Livermore, supra note 4, at s11.

190. Laxminarayan, supra note 29, at 4-7; Laxminarayan \& Weitzman, supra note 171, at 63-67; Marc Lipsitch \& Bruce A. Levin, The Population Dynamics of Antimicrobial Chemotherapy, 41 Antimicrobial Agents \& Chemotherapy 363, 371 (1997) (providing examples of simplifying assumptions in a mathematical model of resistance); Tisdell, supra note 74, at 430.

191. See, e.g., PUJARI ET AL., supra note 5, at 100 ("HAART delivered at FDCs has shown potent and durable effect amongst HIV-infected patients in th is clinical study."); Malaria Resistance, supra note 176 (noting that FDC therapy for malaria may delay the onset of resistance). The U.S. guidelines are at 
progressive but recovery and renewal is possible at some thresholds if the antibiotic is rested. ${ }^{192}$ Others appear to lose effectiveness over time, even without widespread use. ${ }^{193}$ For the last two groups of drugs, one might want extraordinarily tight control early on. If recovery is possible, the drug could be pulled from the market when certain thresholds are reached; for the others, perhaps the threshold triggers a high-use period (the "blowout"). ${ }^{194}$ Yet another strategy would be indicated if a particular microbial population can be reduced so drastically that it will not recover or if ecological controls are partially effective. ${ }^{195}$ Some multiple-drug resistant strains are quite mobile globally and require global coordination, while others are geographically specific and can be addressed on institutional, local, and regional levels. ${ }^{196}$ Alternative strategies are appropriate depending upon the biological response to incremental versus substantial antibiotic innovation. ${ }^{197}$ In short, epidemiological models of resistance are frequently pathogen-specific and context-dependent, while legal models frequently are not. Microbial life and its adaptive responses are exceedingly diverse, and increasingly complex. ${ }^{198}$ In light of such complexity, we should be surprised if a single model of conservation or innovation suited all EPK cases.

The present Article does not map out these myriad possibilities; the underlying science is woefully incomplete. ${ }^{199}$ It merely serves up a warning

http://aidsinfo.nih.gov/guidelines/ (last visited July 10, 2005).

192. See LeVy, supra note 1, at 216-17. For many antibiotics (other than ciprofloxacin), E. coli resistance is temporary and fades within a month. Shannon D. Putnam et al., Postreatment Changes in Escherichia coli Antimicrobial Susceptibility Rates Among Diarrheic Patients Treated With Ciprofloxacin, 49 ANTIMicr obial AgENTs \& CHEMOtherapy 2571-72 (2005) (after treatment with ciprofloxacin, "rates of resistance against multiple antibiotics increased dramatically from baseline to day 7 and then tapered off to return to pretreatment levels by day 28 , except for ciprofloxacin, suggesting that population accumulative usage of fluoroquinolones may result in an incremental increase in resistance rates"); see also supra note 57. Kades takes a strong stand that EPK is finite (like minerals) rather than renewable (like fisheries), which is a much stronger position than may be justified by the complex biological evidence. Kades, supra note 44 , at $662-65$.

193. See Kades, supra note 44 , at $662-65$.

194. Laxminarayan's early work assumed no recovery (i.e., a zero fitness cost). Other work has modeled the possibility of recovery. See Robert Rowthorn \& Gardner M. Brown, Using Antibiotics When Resistance is Renewable, in BAttling Resistance, supra note 29, at 42.

195. James E. Wilen \& Siwa Msangi, Dynamics of Antibiotic Use: Ecological versus Interventionist Strategies to Manage Resistance to Antibiotics, in BATtLING Resistance, supra note 29, at 17.

196. See Livermore, supra note 4 , at s11.

197. Goeschl \& Swanson, supra note $4, \S 3$.

198. Livermore, supra note 4, at s20 (noting that "[a]ntibacterial resistance is complex and dynamic").

199. Id. at s11. See, e.g., Daniel F. Sahm et al., Need for Annual Surveillance of Antimicrobial Resistance in Streptococcus Pneumoniae in the United States: 1-Year Longitudinal Analysis, 45 
that a single legal model is unlikely to address all of the challenges inherent in biological complexity.

\section{Preserving the Public Domain: A Critique of Patent-Based EPK PROPOSALS}

Two broad responses to resistance are possible: (1) conserve EPK to delay resistance and/or (2) stimulate the development of new and innovative drugs. ${ }^{200}$ The former is the demand side response of conservation; the latter is the supply side goal of innovation.

Of course, society must pursue both approaches simultaneously. The principal challenge is to balance the available resources between conservation and innovation, achieving simultaneous solution sets to multiple externality and coordination problems.

The next section applies the framework developed thus far against recent patent proposals concerning antibiotic resistance. The first proposal focuses primarily on private conservation of EPK through expanded IP rights; the second focuses on promoting EPK innovation through expanded IP rights. Both proposals expand the patent domain at the expense of the public domain.

\section{A. Conservation of EPK Through Extended Patent Terms}

Eric Kades has explored patent-based conservation of EPK in his recent article, Preserving a Precious Resource: Rationalizing the Use of Antibiotics. ${ }^{201}$ This attention is focused upon consumer waste: the problem of current low-value usage of antibiotics (treatment of minor infections) which exhausts the resource and prevents its effective utilization in subsequent highvalue situations (life-threatening infections). ${ }^{202}$ Kades claims the consumer

Antimicrobial Agents \& Chemotherapy 1037-42 (2001) (concluding that more resources should be devoted to tracking the changes in antibiotic resistance on a more frequent basis).

200. Goeschl and Swanson describe it as follows: "either (a) slow the rate of arrival of biological problems; and/or (b) increase the rate of arrival of solutions to such problems." Goeschl \& Swanson, supra note $4, \S 2$.

201. Kades, supra note 44, at 643. Prior work on the patent-antibiotic resistance interface includes Laxminarayan's 2002 article in the Journal of Agricultural Economics. See supra note 71. Kades cites to Laxminarayan, see Kades, supra note 49, at 634 n.92, but not for this work.

202. Id. at 626-29. Brown and Layton also highlight the privately maximizing individual who ignores the impact of therapeutic antibiotic use on others. Brown \& Layton, supra note 54, at 355. To be clear, they have not proved that individuals do act in this way; they have only assumed that if individuals are rational individual maximizers, and if they take no ac count of the negative externalities from their antibiotic use, then they will overuse antibiotics from a social-welfare perspective. Imposing Pigovian rents to 
must internalize these costs in order to avoid waste: "Unless there is some mechanism to force consumers to bear this cost when they buy antibiotics, they will ignore it and the populace will overuse antibiotics relative to the socially optimal level." ${ }^{203}$ Kades also identifies the broader problem of waste by the patent holder and in the public domain, which is broadly consistent with my discussion above. ${ }^{204}$

We part company when Kades proposes expanded IP rights as a conservation tool. In his view, EPK patent periods should be extremely long. ${ }^{205}$ Kades argues that much longer patent terms reduce the firm's proclivity to waste. Likewise, expanded patent rent extraction from consumers operates as a Pigovian tax to dampen consumer waste. ${ }^{206}$ The proposal stands or falls on whether it succeeds as a conservation system for EPK.

\section{Conservation Through Pigovian Rents}

Kades addresses patent holder waste by delaying the day of reckoning. This point is well taken. If patents never expire, then we do not have to worry about waste caused solely by time-limited property rights. ${ }^{207}$

But we have many other types of waste to be concerned about. Firms generally operate with a limited time horizon. With quarterly earnings targets to meet, a publicly traded pharmaceutical company with perpetual patents

optimize antibiotic use is the natural extension of these assumptions.

203. Kades, supra note 44, at 626.

204. Id. at 625-67.

205. Id. at 651 .

206. "This section makes a novel and radical argument that patent terms for antibiotics should be extremely long." Id. at 614 . Kades's argument is that public health would be maximized by granting longterm or much longer patents for drugs that lose effectiveness with use, such as antibiotics. Id. at 643-53. A patent holder rationally maximizes sales during the exclusive marketing period, even for uses which are medically marginal. From a public health perspective, this practice speeds the development of resistant strains of bacteria or viruses. Global public health would be maximized by extending the exclusive marketing period indefinitely and encouraging judicious use of the drug in the most compelling cases. $I d$. at 614. Philipson and Mechoulan have primarily made Kades's "novel" point when they conclude that the optimal patent life is infinite if the good creates negative externalities, giving antibiotic resistance as one example. Tomas J. Philipson \& Stéphane Mechoulan, Intellectual Property \& External Consumption Effects: Generalizations from Pharmaceutical Markets 9, 13-14 (Nat'l Bureau of Econ. Research, Working Paper No. 9598, 2003). Establishing longer or perpetual patents for antibiotics would be a complete reversal of pre-Hatch-Waxman policy, which restricted special generic entry only to antibiotics. 21 U.S.C. 357 (1996), amended by Pub. L. No. 105-115, § 125(b)(1), 111 Stat. 2325 (1997). While the Hatch-Waxman Act expanded the generic entry process to other drugs, 21 U.S.C. § $355(\mathrm{j})(2000)$, the special generic entry process for antibiotics was not repealed until 1997.

207. See supra Section II.A. 
might still be tempted to sell more now rather than later. ${ }^{208}$ Kades assumes that longer patent terms will enable holders to optimize their marketing, saving important drugs for their highest and best uses. A recent article from Wyeth Pharmaceuticals, a major marketer of antibiotics, suggests that this faith may be misplaced. That author argued for more aggressive use of antibiotics, even for upper respiratory infections which were viral rather than bacterial. He explicitly denied the need to balance larger social needs ("we cannot elevate the goal of preventing resistance above our primary responsibility of treating infected patients") and advocated a very different treatment protocol than Kades: "antibacterial treatment must only be denied when there is a near certainty that the patient will derive no benefit." ${ }^{209}$ Fischer and Laxminarayan have argued that monopolists facing multiple markets extract exhaustible resources more rapidly than socially optimal. ${ }^{210}$ EPK still needs to be managed while in the patent domain. Kades proposes to let drug companies manage EPK with expanded pharmaceutical appropriation rents. It is hoped that these Pigovian rents ${ }^{211}$ will squeeze lessvaluable uses out of the market. ${ }^{212}$ This neoclassical model simplifies the reality of pharmaceutical markets in several unfortunate respects as addressed in the following paragraphs.

\section{(a) Heterogeneous Externalities}

A major difficulty with Pigovian rents is the heterogeneity of externalities, requiring many different rents which vary over time, place, and use. $^{213}$ The rent should correspond with the particular externality. Take the

208. Put another way, firms may employ idiosyncratic discount rates when making intertemporal comparisons.

209. Steven J. Projan, Why is Big Pharma Getting out of Antibacterial Drug Discovery?, 6 CURRENT OPINION IN MiCROBIOLOGY 427, 428 (2003).

210. Carolyn Fischer \& Ramanan Laxminarayan, Monopoly Extraction of an Exhaustible Resource with Two Markets, 37 CAN. J. Econ. 178-88 (2004).

211. Pigovian rent (a possible neologism) is my term for Kades's goal: to use patent rents for Pigovian purposes.

212. Kades nowhere explicitly says that Pigovian rents will be administered solely through pharmaceutical appropriation rents, but several times it is assumed. For example, he states that actors "on the ground" will be able to set optimal Pigovian rents much better than government. Kades, supra note 44, at 637. On the subsequent page it appears that some element of the tax will be set by government fiat, namely, the rising tax to account for the time value of money. Id. at 638-39. He later suggests that the deadweight losses (sales prices above the marginal cost of production, i.e., patent rents) are the mechanism to reduce unnecessary use. $I d$. at 645 .

213. Kades sidesteps these "calibration" issues. Id. at 644. Brown and Layton acknowledge the potential for heterogeneity, but assume it away to simplify their model. Brown \& Layton, supra note 54, 
example of animal feed use of antibiotics. Kades wants animal feed taxed out of the market first, ${ }^{214}$ but the medical evidence is unclear as to the nature and strength of the linkages between animal use and human resistance. Veterinary use may create less of an externality than inappropriate human use. ${ }^{215}$ Pigovian rents on animal use should likewise vary across different drugs and uses and over time as the scientific understanding changes. In any event, the U.S. FDA can ban antibiotic agents in animal feed when confronted with clear evidence, as demonstrated by its July 2005 action against the use of Baytril in poultry. ${ }^{216}$

In human use, the externalities vary widely. For antibiotics which exhaust quickly, the negative externality of inappropriate use is quite high, while for others, the opposite will be true. A particular drug can generate different externalities in different uses and users. Hospitals produce greater resistance externalities per pound of antibiotic used; community use creates less resistance per pound. ${ }^{217}$ Non-prescription antibiotic use in household devices may be another category. Pigovian rents would have to vary by these factors as well. ${ }^{218}$

Pharmaceutical products are usually priced by product, geography, and payor rather than intended use. Arbitrage between uses could be expected to develop, undermining the Pigovian effect. While it might certainly be possible to segment animal and human markets, arbitrage within the community pharmacy or hospital ICU would be a daunting barrier. Arbitrage across the Canadian border has been hard to stop, ${ }^{219}$ arbitrage within domestic markets will be more difficult still, because the legal tools to hinder cross-

at 353 n.6. Brown \& Layton conclude that a social planner would need detailed information on antibiotics and resistance. Id. at 355. See also supra Section II.D.6 on biological complexity and heterogeneity and sources cited therein.

214. Cf. Kades, supra note 44 , at 618,639 .

215. Glycopeptide use in animals and humans may not create the same level of externalities due to biological differences between humans and domesticated animal species. This point is sometimes missed in the debates over animal use of antibiotics. See, e.g., Gould, supra note 168, at 701-03; WARREN KAPLAN \& Richard Laing, WHO, Priority Medicines for Europe and the World 48-53 (2004), at http://mednet3.who.int/prioritymeds. For a sophisticated treatment, see Laxminarayan, supra note 71, at 1287-92.

216. Anna Wilde Mathews \& Zachary Goldfarb, FDA Bans Use of Antibiotic in Poultry, Wall ST. J., July 29, 2005, at B1.

217. Gould, supra note 168, at 706; MacKenzie \& Gould, supra note 49, at 105 ("Although the greatest use in human medicine is in the community, it is the intensive use of antibiotics in our hospitals that has the greatest impact on resistance.").

218. For mathematical models of the emergence of resistance to different treatment regimes, see Lipsitch \& Levin, supra note 189, at 363.

219. Pharmaceutical Arbitrage, supra note 13, at 277-80. 
border pharmaceutical arbitrage are not generally available within a common market such as the U.S.

\section{(b) Heterogeneous Consumers}

Consumers are also heterogeneous. In the U.S., the demand elasticity for drugs is quite low, particularly among the wealthy and those with third-party insurance for drugs. ${ }^{220}$ Low-income uninsured populations exhibit a more elastic demand curve. ${ }^{221}$ Rates of resistance are higher in children, ${ }^{222}$ requiring adjustment for the age of the patient. A flat Pigovian rent might reduce utilization, but it would be relatively ineffective among the rich, and far too effective among the poor. The wealthy would still engage in consumer waste, ${ }^{223}$ the poor would forego therapeutically important drugs. ${ }^{224}$

One possible solution would be to vary Pigovian rents with the wealth of the consumer, or more precisely, their willingness to pay. This possible solution is actually a proposal for perfect price discrimination, a very unlikely proposal. ${ }^{225}$ Consumers will not willingly disclose their financial information

220. See, e.g., A. Leibowitz, W.G. Manning \& J.P. Newhouse, The Demand for Prescription Drugs as a Function of Cost-Sharing, 21 Soc. SCI. Med. 1063-69 (1985) (noting that cost-sharing affects the use of prescription drugs); John D. Piette, Michele Heisler \& Todd H. Wagner, Cost-Related Medication Underuse: Do Patients with Chronic Illnesses Tell Their Doctors?, 164 Archives InTER nal Med. 1749, 1749-55 (2004) (survey of older American adults with chronic illnesses who reported underusing medication due to cost); Vincenzo Atella et al., Affordability of Medicines and Patents' Cost Reduction Behaviors: Empirical Evidence Based on SUR Estimates From Italy and the United Kingdom 2 (Ctr. of Int'l Studies on Econ. Growth, Working Paper No. 71, 2005), available at http://www.ssrn.com/ abstract $=648009$ ("Demand for prescription drugs is reduced by a direct contribution from the patient, even though the overall impact of co-payment remains quite limited, with price elasticity ranging between -0.1 to $-0.6 . ")$.

221. For an example of these effects, see W. Nordhaus, Invention, Growth \& Economic Welfare 81-86 (1969); Klaus Deininger \& Paul Mpuga, Economic and Welfare Effects of the Abolition of Health User Fees: Evidence from Uganda 1, 19 (World Bank Policy Research, Working Paper No. 3276, 2004) (noting that demand for health services in Uganda is elastic, thus the abolition of health user fees improved access and reduced the probability of sickness, especially for the poor); see also F.M. Scherer \& J. Watal, The Economics of TRIPS Options for Access to Medicines, in EssEnTIAL MEDiCINES, supra note 28, at 44.

222. Karlowsky et al., supra note 151, at 963-70 (demonstrating statistically significant rates of resistance to penicillin, azithromycin, TMP-SMX, and ceftriaxone amongst persons under 18).

223. Health plans marketed to the rich might well tout their less restrictive plan design. The very wealthy can purchase antibiotics at any market price and may have a near-zero demand elasticity.

224. The patients who will be most sensitive to the price mechanism (Pigovian rent) will be the nonwealthy uninsured. In low-income countries, antibiotic resistance is driven more by underutilization. Byarugaba, supra note 110, at 617, 633-35.

225. Kades, supra note 44, at 647-48. For an extended discussion of price discrimination in pharmaceutical markets, see Pharmaceutical Arbitrage, supra note 13, at 203-08. 
to pharmaceutical companies so that pricing can be adjusted accordingly, particularly when it must be combined with patient-identifiable clinical information on health status. Accounting for these factors will require drug companies to obtain and utilize massive amounts of patient-specific clinical information before a pricing decision becomes final. Even in the absence of medical privacy, opportunities for arbitrage and cheating would abound, undermining the salutary effect of the Pigovian rents.

Kades suggests that drug firms might segment markets for price discrimination purposes by differential branding of the same drug within the U.S. market. ${ }^{226}$ This is unlikely to work within the U.S. market so long as physicians are permitted to prescribe for off-label uses, a major feature of U.S. prescription markets. ${ }^{227}$ Fischer and Laxminarayan predict non-efficient use of exhaustible resources by monopolists facing multiple markets, even with or without price discrimination and arbitrage..$^{228}$

Another weakness of enhanced price discrimination is that it gives too much market power to drug companies. Once perfect price discrimination is in place, companies will wield near-total market power without any guarantee that the result will serve public health. Noonan predicts non-optimal results from a patent holder's control over genetic resistance resources. ${ }^{229}$ Patent holders could induce further demand through pharmaceutical promotion, ${ }^{230}$ armed with patient-level prescription and financial data. No market tool would be available to police the near-total appropriation of consumer surplus. Indeed, drug companies could conceivably extract appropriation rents in excess of consumer surplus.

Kades concedes that EPK requires a heterogeneous Pigovian rent in at least one circumstance. He proposes a rising tax to account for the rate of inflation. ${ }^{231}$ Heterogeneity is addressed primarily in the context where it is

226. Kades, supra note 44, at 647.

227. The FDA permits a physician to prescribe an approved drug for any use, including a use not specified on the label (an "off-label" use). The FDA Final Rule on Dissemination of Information on Unapproved/New Uses for Marketed Drugs, Biologics, and Devices was published on November 20, 1998. 63 Fed. Reg. 64556 (Nov. 20, 1998). On June 16, 2005, the FDA solicited additional comments on this rule. 70 Fed. Reg. 35099 (June 16, 2005). Kades's domestic price discrimination plan would collapse once physicians switched to off-label prescriptions of the cheaper drug.

228. Fischer \& Laxminarayan, supra note 210 , at 178-88.

229. Noonan, supra note 71, at 263-87; see also Fischer, supra note 71, at 288 .

230. Rational Use, supra note 102, ๆ 26 ("Pharmaceutical promotion often has negative effects on prescribing and consumer choice, but regulation of promotional activities has been proven to be one of the few effective interventions."). Kades appears to assume that the negative effects of drug promotion will cease under a perpetual patent regime.

231. Kades, supra note 44, at 638. 
easiest to model: the time value of money. Adjusting Pigovian rents only for inflation ignores many other biological and clinical complexities which might call for significant adjustments. These effects are likely to swamp the timevalue price increase modeled in Preserving a Precious Resource.

Greatly extending patents seems like overkill when one recognizes that only 5 conditions account for $75 \%$ of all unnecessary ambulatory antibiotic prescriptions. ${ }^{232}$ Experts suggest that 3 conditions should be targeted to substantially reduce community abuse of antibiotics: urinary tract infections, pharyngitis, and bronchitis. ${ }^{233}$ In other words, consumer EPK waste ${ }^{234}$ could be largely addressed by targeting these 3 conditions, rather than embarking upon a major revision of the global pharmaceutical patent system.

\section{(c) Biological Complexity}

Kades makes assumptions about antibiotic resistance which are inappropriate in some cases. The model breaks down for some diseases and some antibiotics, making a uniform extension of all EPK patents inappropriate. Several examples illustrate the point.

Kades models antibiotic resistance as gradual and proportional, ${ }^{235}$ borrowing heavily from models of mineral exhaustion. ${ }^{236}$ Recall the discussion on the biological complexity of resistance in Section II.D.6 above. For each of those examples, a different optimal use pattern may be appropriate. $^{237}$ For example, assume that the optimal use pattern for a particular situation is cycled through various restrictions over a long period of time as resistance slowly builds towards a clinically determined threshold.

232. Gonzales et al., supra note 77 , at 757-60.

233. Id. at 760 .

234. Institutional waste (i.e., in hospital ICUs) is not included in this analysis.

235. Kades, supra note 44, at 614-35. Brown and Layton employ the same assumption, but conclude that the social planner requires detailed information on antibiotics and resistance. Brown \& Layton, supra note 54 , at 353,355 .

236. In particular, the "Hotelling Rule." Kades, supra note 44, at 629-35. The economics of pricing exhaustible resources is discussed by Louis Phlips, The ECONOMics of Price Discrimination 111-33 (1983), including his interesting modification to Coase, $i d$. at 125-29.

237. Clem Tisdell makes this point explicitly in the 1982 article that Kades celebrates as seminal. Tisdell, supra note 74, at 430; Kades, supra note 44, at 638. Kades also states that "Clem Tisdell was the first to point out this problem, in an article inexplicably ignored by subsequent scholarship." Kades, supra note 44, at 626. Tisdell has been cited by others prior to Kades; for example, in Ramanan Laxminarayan's excellent book, BATTLING ResistAnCE, supra note 29, at 14. See also the excellent collection of articles in BAtTling Resistance, supra note 29. 
Once the threshold is reached, widespread use is called for (the "blowout"). ${ }^{238}$ Modifying patent length to fit this use pattern is not simple. ${ }^{239}$

Consider some of the other cases of biological complexity. Some drugs should be used in rotation. Instead of a blowout, the drug should be put on the shelf for a while and not used at all. A perpetual patent here is one option, but the clinical issue could be more directly addressed by temporarily withdrawing FDA marketing approval rather than a patent change. ${ }^{240}$ Other drugs will require one set of conservation techniques in the community and an entirely different strategy in the ICU. Some microbes have not developed resistance to a particular antibiotic despite half a century of use. ${ }^{241}$ Others develop resistance much more quickly. ${ }^{242}$ Prismatic and shifting patent rights in these circumstances appear to be very complex and would invite arbitrage, abuse and error.

Preserving a Precious Resource also does not address the complexities of class effects and the need for FDCs. ${ }^{243}$ For some drugs, the unit of conservation must be the class, not merely the drug or its patents. FDCs frequently contain drugs from multiple classes. Malaria, a major global public health crisis, will require coordinated subsidies of FDC drugs from multiple classes. $^{244}$ To account for these conditions requires patents which are extraordinarily broad, in addition to eternal. ${ }^{245}$ A single firm must own perpetual rights to an entire class of antibiotics. When resistance crosses classes, or where FDCs are indicated, multiple classes must be joined together. This is hardly a market-based approach, but instead a remarkable expansion of market power and concentration in the hands of a single pharmaceutical firm in the hope that the firm will manage utilization for the

238. For a discussion on mathematical models of resistance, comparing combination therapy with cycling, see White, supra note 4, at 90-91.

239. Perhaps the patent could expire on the blowout date, but then most of the rents would be denied to the innovator. If the patent expires long after the blowout date, nothing of value enters the public domain.

240. If innovation incentives were inadequate (a fact to be proven, not assumed), then a HatchWaxman extension of patent rights during the shelf period might be appropriate.

241. Gould, supra note 168, at 704 (noting how penicillin resistance has not developed in Streptococcus pyogenes "despite over 50 years of intense exposure").

242. Id. at 704-05.

243. Close competitors and class effects are discussed, but the negative implications for extending patent forms is left unexamined. Kades, supra note 44, at 623.

244. Malaria Resistance, supra note 176, at 9-13.

245. See Ramanan Laxminarayan, Economic Responses to the Problem of Drug Resistance, in THE Resistance Phenomenon in Microbes and Infectious Disease Vectors: ImPlications for Human Health And Strategies for Containment 126 (Stacey L. Knobler et al. eds., 2003). 
highest good of the planet. GlaxoSmithKline holds a 45\% global market share in ARVs for the treatment of AIDS. ${ }^{246}$ The experience of the last decade with the AIDS treatment crisis should not encourage us to give GlaxoSmithKline the whole ball of wax. These concerns cannot be relegated by Kades to another day; they may well compel a radically different policy than extended IP rights.

\section{(d) Health Care Consumer Behavior}

The neoclassical model assumes that patients will make wise choices on antibiotic usage under the influence of Pigovian rents. ${ }^{247}$ Preserving $a$ Precious Resource utilizes an example of cost-benefit analysis by a rational patient which is unrealistic ${ }^{248}$ given the realities of the health care market. It is assumed, rather than proven, that private decentralized actors (e.g., physicians, patients, pharmacists, drug representatives) will collect and use superior information to maximize the exhaustible resource in response to Pigovian rents. ${ }^{249}$ The literature on irrationality, conflicts of interest, information costs, and third-party payments in pharmaceutical markets is large and persuasive, and needs to be addressed before such a position can be taken seriously. ${ }^{250}$ Physicians and patients make many terrible decisions on medical care. Even complex and dangerous heart surgeries are subject to inappropriate choices. ${ }^{251}$ The quality of information and decision making is unlikely to be greater on lower-profile pharmaceuticals. ${ }^{252}$

246. Glaxo's HIV Drugs Come Under Pressure, Wall St. J., Sept. 22, 2003, at B3 (45\% global market share); see also GlaxoSmithKline PLC, Annual Report (Form 20-F), at 25 (Mar. 8, 2005) (antiretroviral sales data), available at $\mathrm{http} / / / \mathrm{www} . \mathrm{sec}$.gov/edgar/searchedgar/companysearch.html (last visited June 22, 2005).

247. See Kades, supra note 44, at 639 tbl. 4.

248. Id. at 640. The emphasis on testing and diagnostics is laudable, but the assumed rationality of the patient as an economic actor does not comport with reality.

249. See id. at 626 ("Unless there is some mechanism to force consumers to bear this cost when they buy antibiotics, they will ignore it and the populace will overuse antibiotics relative to the socially optimal level.”) (suggesting that higher prices will sort high-value from low-value pharmaceutical use).

250. Richard Frank provides a helpful introduction to behavioral economics literature in health care. See generally Richard G. Frank, Behavioral Economics and Health Economics (Nat'l Bureau of Econ. Research, Working Paper No. 10881, 2004), available at http://www.nber.com/papers/w10881.

251. Up to 769 former patients at Redding Medical Center have sued for unnecessary invasive procedures such as cardiac catheterizations and coronary artery bypass grafts. The hospital settled for $\$ 395$ million and four referring cardiologists settled for \$24 million. Laura Mahoney, Redding Cardiologists Pay \$24 Million To Settle Claims From 769 Surgery Patients, 14 BNA Health L. ReP. 97,97 (Jan. 20, 2005). The suit alleged that the physicians were tempted by fees to perform unnecessary heart surgeries. Id.

252. For a discussion on the sources of inappropriate patterns of antibiotic prescribing, see Arnold, 
Two examples should lay down the gauntlet. First, Preserving a Precious Resource sidesteps the growing ubiquity in the U.S. of third-party payments for prescriptions, both in community settings and in the institutions where antibiotic use is highest. ${ }^{253}$ If Pigovian rents are placed on the health plan, then the consumer is isolated from the attempt to internalize the cost, and consumer waste is not modified.

If the rent is borne by the health plan, but some cost is to be passed through to employees or beneficiaries, then the health plan will regulate antibiotic usage with managed care techniques. Since the goal here is not cost savings, but optimizing conservation of EPK, the techniques would have to be heterogeneous. ${ }^{254}$ Common techniques for drugs include prior authorization, disease management, tiered co-pays, education, and academic detailing. ${ }^{255}$ For example, the co-pay for an antibiotic for a child's sore throat might vary from $\$ 0$ to $\$ 1,000^{256}$ depending upon factors such as clinical history, an in-office strep test, the antibiotic prescribed, and financial resources. Other tools attempt to raise the quality of information provided in the health care marketplace. For example, Medicare is now attempting to improve the quality of physician and hospital practices by paying bonuses for meeting quality targets. ${ }^{257}$ Quality advocates are attempting to improve hospital infectioncontrol practices through public disclosure of infection data. ${ }^{258}$ Cruise ship companies are scrambling to implement infection-control policies before the

supra note 99 , at 494 .

253. Reimbursement for outpatient prescription drugs is growing, particularly after the passage of the new Part D Medicare Drug Benefit. Medicare Prescription Drug and Modernization Act of 2003, Pub. L. No. 108-173, 117 Stat. 2066. Antibiotic usage is particularly intense in inpatient hospital settings, where the costs are often included within case-billed reimbursement systems such as the Medicare Prospective Payment System. Third-party reimbursement in the rest of the high-income world is even more pervasive. The December 2004 meeting of the WHO Executive Board recommended the extension of third-party payment mechanisms for essential medicines for low-income populations, using the insurance systems to promote more rational usage. Rational Use, supra note 102, ๆๆ 14-18.

254. If one allows each health plan to make its own choices here, some will market themselves to the wealthy as plans with fewer restrictions. On the other hand, if one constrains health-plan choice, the government is conserving EPK.

255. Arnold, supra note 99, at 497, 500-19 (providing a systematic review of all published studies on interventions to improve antibiotic prescribing). Only one of Arnold's 11 categories employs financial incentives, and the published literature is weak on the effectiveness of financial incentives to reduce prescriptions of antibiotics and antibiotic resistance. $I d$. at 511, 518-19.

256. This figures assumes a Pigovian rent significant enough to influence consumer behavior. For very wealthy consumers, $\$ 1,000$ might be too little to meet Kades's goal of socially optimal prescribing.

257. Sarah Lueck, Medicare to Pay Bonuses to Doctors For Cutting Costs, Wall St. J., Feb. 1, 2005 , at A2.

258. Rhonda L. Rundle, Germ Reports: Some Push to Make Hospitals Disclose Rates of Infection, Wall St. J., Feb. 1, 2005, at A1. 
Centers for Disease Control and Prevention publish data on viral and bacterial outbreaks on ships. ${ }^{259}$

The ubiquity of such tools begs the question: Why bother with greatly extended patents? If conservation ultimately depends upon managed care techniques after the long trickle down from greatly extended patents and Pigovian rents, it seems easier and more efficient to do so directly.

Second, rational allocation is unlikely because of severe informational problems endemic to health care. Kades wants to "allow the parties 'on the ground' dealing with the problem to draw on their superior information when they decide where and when to economize on the use of a taxed resource."260 This is not an accurate description of a typical physician-patient encounter. Physicians and patients are overwhelmed with the complexity of clinical information on infectious diseases and available therapies. ${ }^{261}$ Health plans strictly limit the time the physician can spend with a patient and the effort the physician can expend on tailoring the treatment to the patient's unique needs. ${ }^{262}$ Much of the needed information is unknown to the clinicians ${ }^{263}$ and is even more remote from drug companies who would be calibrating the incentives. In the absence of good information, consumer waste returns. ${ }^{264}$

Other significant users of antibiotics operate with better information, particularly a hospital ICU choosing an antibiotic regime for a patient. But it might be better still to allow the hospital to treat patients based solely on evidence-based medicine. Imposing Pigovian rents on hospitals for noncompliance with the patent owner's clinical instructions seems to be a

259. Evan Perez \& Betsy McKay, Cruise Lines Press for New Term to Describe Viral 'Outbreak', Wall St. J., Feb. 8, 2005, at B1.

260. Kades, supra note 44, at 637.

261. See, e.g., Avorn \& Solomon, supra note 10, at 128-30 (describing factors leading to antibiotic misuse). Several resolutions concerning drug advertising were considered by the American Medical Association's (AMA) House of Delegates at its 2005 Annual Meeting. In general, these resolutions bemoaned the poor quality of information delivered to patients through pharmaceutical company direct-toconsumer advertising. AMA 2005 Annual Meeting, Reports and Resolutions (Reference Committee E), Resolutions 507, 519, 524, 532, 533, and 536, available at www.ama-assn.org/ama/pub/category/15078. $\mathrm{html}$ (last visited June 20,2005). Under intense lobbying pressure from drug companies, the AMA deferred the question to a study committee until next year.

262. More precisely, payors primarily control reimbursement. Physicians can spend all day with the patients if they want to, but the health plan will only pay for a 15-minute visit.

263. See Gavin Barlow, Pneumonia Guidelines in Practice, in AntiBiotic Policies, supra note 4, at 39 (discussing interventions in cases of community-acquired pneumonia (CAP)).

264. A better option would be to improve the knowledge base so that EPK could be more effectively managed. Kades's suggestions on subsidizing diagnostic R\&D fall into the category. Kades, supra note 44, at 639-41. This idea, while laudable, does not require longer patent terms. For discussions along this line, see infra Section III.A.3 below. 
significant move away from a free market ${ }^{265}$ without providing proof of better outcomes.

A more likely path is to improve the quality of information available to the decision makers. Kades dismisses such antibiotic conservation programs as "jawboning," 266 but empirical studies support the efficacy of some programs to reduce unnecessary antibiotic use. ${ }^{267}$ Kades simply presumes that "hard" incentives will be more effective, without empirical support. ${ }^{268}$ Studies suggest that EPK conservation problems are much broader than the simple selection of the wrong drug, and include problems with inappropriate dosage, timing, compliance, and regimes. ${ }^{269}$ Likewise, EPK conservation involves many interventions, including antibiotic policies, formularies, prescription guidelines, audits, and enforcement. ${ }^{270}$ Pigovian rents would have to be extraordinarily detailed and complex to successfully improve clinical practices.

The limited empirical data do not support a case for Pigovian rents as the primary EPK conservation tool. In a study of antibiotic consumption amongst high-income countries, the U.S., with the highest prices in the world, ranked in the middle. French consumption was nearly 50\% higher, followed closely by Spain and Portugal. Countries with significantly lower consumption included the United Kingdom, Sweden, Austria, Germany and the Netherlands. ${ }^{271}$ Since the U.S. enjoys both the highest prices and a strong pharmaceutical appropriation environment, ${ }^{272}$ it is hard to make a case that the significant variations in antibiotic consumption are due to domestic financial factors. In the community setting, the two most reliable studies on financial

265. Kades asserts that "[t]he patent system is thus part and parcel of a market economy" and both "are necessary evils." Kades, supra note 44, at 644-45. However, they are not necessary; alternatives are on the table especially after discovery and the granting of the patent. For example, Kades also discusses patent buyouts, but assumes that all of the evils of mariginal cost pricing must follow the buyout. This is certainly not correct. $I d$. at 646 .

266. Id. at 635-38.

267. Kades, supra note 44, at 638 ("For these reasons, this Article proceeds on the premise that 'hard' economic incentives such as taxed, subsidies, and changes in patent rights are much more effective measures that legislative fiat, jawboning, and education.”). For a review of the literature on measures to reduce inappropriate antibiotic prescriptions, see generally Arnold, supra note 99; Avorn, supra note 10; and Parrino, supra note 10.

268. See Kades, supra note 44.

269. Phillips, supra note 143, at 10.

270. Erwin M. Brown, Intervention to Optimize Antibiotic Prescribing in Hospitals: The UK Approach, in ANTIBIOTIC Policies, supra note 4, at 163-76.

271. Sigvard Mölstad \& Otto Cars, Antibiotic Use in the Community, in Antib Iotic Policies, supra note 4 , at 569 .

272. By this, I mean the highest degree of pharmaceutical appropriation. 
incentives for antibiotic conservation utilized formularies and primary care reforms. ${ }^{273}$ Both techniques can be implemented without modifying patent law.

Some lessons can be drawn from tobacco control where a combination of education, legal restrictions and taxes have reduced utilization. A key distinction between nicotine and other drugs is that there are no therapeutic uses of nicotine. If restrictive measures regarding nicotine are too powerful, no one is denied access to a lifesaving product. The clinical markets for antibiotics are much more complex, and the stakes for under-utilization are much higher, particularly for the poor who are most vulnerable to inappropriate rationing by price.

The most effective intervention to conserve EPK may be infection control and better diagnostic tools. ${ }^{274}$ The least complicated intervention would be a subsidy for these practices.

\section{(e) Globalization and TRIPS}

While Preserving a Precious Resource focuses primarily on domestic conservation of EPK, the biology of resistance necessitates global conservation in some cases, with the caveats expressed in Section II.D.1 above. Globalization makes the conservation of exhaustible drugs a planetary priority. Actions by the United States to manage resistance might be laudable, and locally effective to some degree, but will not be fully effective absent effective global coordination mechanisms. Control of malaria may be ineffective unless FACT is subsidized and diversified across all endemic regions. ${ }^{275}$ Kades acknowledged the international coordination issue, ${ }^{276}$ but simply hopes that each democracy will select either Pigovian taxes or much longer patents. After the TRIPS Agreement, the global appetite for longer pharmaceutical patents seems to be quite limited, ${ }^{277}$ and Pigovian taxes on antibiotic use stands in marked contrast to the social insurance models in

273. Arnold, supra note 99, at 510-11.

274. Extensive literature documents the effectiveness of infection control. See, e.g., Hakan Hanberger et al., Intensive Care Unit, in AnTibiotic Policies, supra note 4, at 273-74. Kades concedes the need for better diagnostic tools. Kades, supra note 44, at 639-41. No change to antibiotic patents is necessary in order to subsidize diagnostics, nor would Pigovian rents be required. Society would be better off with the subsidized diagnostic tools at marginal cost, stripped of patent rents. The diagnostic tools themselves should not suffer from the overutilization problem plaguing EPK generally.

275. Malaria Resistance, supra note 176, at 1, 2 \& n.5.

276. Kades, supra note 44, at 669-71.

277. See the discussion in the next paragraph infra. 
Canada, Australia and the EU. Indeed, it is hard to politically imagine antibiotic Pigovian taxes on U.S. beneficiaries of Medicaid or the Medicare Part D drug benefit. But putting aside these questions of practical politics, price differences would be created if one country adopted Pigovian taxes, another chose much longer patents, and a third followed neither course. Price differences (and, thus, arbitrage pressure) in each country would be accentuated by non-uniform adoption of these policy options. ${ }^{278}$ Kades acknowledges these global coordination problems as a "weakest link" in his proposals, but does not otherwise articulate solutions. ${ }^{279}$

Global extensions of pharmaceutical patent terms will run afoul of the TRIPS agreement. It is highly unlikely that low- and middle-income countries will agree to extend antibiotic patent terms. Indeed, the goal of the essential medicines movement has been to reduce the extraction of patent rents and other forms of pharmaceutical appropriation from low- and middle-income populations. The TRIPS agreement is unlikely to be a global coordination mechanism to extend EPK patents significantly. ${ }^{280}$ The proliferation of the TRIPS agreement and provisions in U.S. free trade agreements are minor adjustments compared to this major proposed change. TRIPS is more likely to act in the opposite capacity, as a rallying point against patent extensions. Perpetual patents would require special treatment for a subset of pharmaceutical patents; effectively, a TRIPS exception for EPK patents. This would likely violate TRIPS nondiscrimination principles, at least if the views of the United States Trade Representative Office(USTR) remain consistent. ${ }^{281}$

Kades's proposal amounts to expanding TRIPS with much longer patents for EPK. Issues of access and equity are shifted to counterproductive prescription subsidies or the goodwill of pharmaceutical companies. Lowand middle-income communities are placed at the mercy of voluntary differential pricing programs and drug company charity, which have been demonstrated to be inadequate to the global health task. ${ }^{282}$

278. Pharmaceutical Arbitrage, supra note 13, at 205-16 (theory of pharmaceutical arbitrage), 275-91 (cross-border pharmaceutical arbitrage from Canada to the U.S.).

279. Kades, supra note 44, at 653-54, 671.

280. The proliferation of TRIPS + provisions in U.S. free-trade agreements are minor adjustments compared to this proposed change.

281. Outterson, Agony in the Antipodes, supra note 66, at 320 \& n. 34 .

282. Pharmaceutical Arbitrage, supra note 13, at 222-27. 


\section{(f) Planning for the Plague Year}

Preserving a Precious Resource places particular emphasis on the dangers of a major epidemic. ${ }^{283}$ The patent system seems a particularly awkward mechanism to horde drugs for a global epidemic. Pharmaceutical firms are unlikely to hold powerful drugs in reserve for the plague year. ${ }^{284}$ Even with much longer patents, the firm must expect revenues, and market revenues may not arrive until the epidemic. Firms have difficulty modeling the "big payday" of a plague. The timing is uncertain at best. The revenues are even more uncertain. Once the plague hits, market pricing may not prevail, without regard to patent status. During an epidemic, governments might attack "price gouging" and impose severe price controls. In the face of an anthrax scare in the U.S., Bayer felt this pressure most acutely. ${ }^{285}$ Longer patents do not resolve this time-consistency problem. ${ }^{286}$

Even under perpetual patents, firms would require credible commitments to a discounted cash flow. Possible market-making techniques include patent buyouts, prizes, strategic stockpiles, and contractual purchase commitments. ${ }^{287}$ Most importantly, if these techniques succeed in making a market for the unknown plague year, then the special case for longer patents evaporates. If the time-consistency problem can be solved for an uncertain plague far in the

283. Cf. Kades, supra note 44 , at $653-54$.

284. Even with a perpetual patent, it is unlikely that Bayer would halt sales of Cipro until an anthrax attack. Patients at risk of dying in the meantime for want of Cipro might have ethical or legal claims against Bayer. For an account of social upheaval during a plague, see Daniel Defoe, A Journal of The Plague Year (Louis A. Landa ed., Oxford Univ. Press 1998) (1722).

285. Jill Carroll \& Ron Winslow, Bayer To Slash Price U.S. Pays for Cipro Drug, Wall St. J., Oct. 25, 2001, at A3 ("The agreement comes after a high-stakes threat by Tommy Thompson, HHS secretary, to break Bayer's patent for Cipro if he didn't get the price he wanted."). The U.S. compulsory license statutes are 7 U.S.C. $\S 2404$ (2000) (patents necessary for the nation's food supply); 17 U.S.C. $\S 115$ (2000) (copyrights to certain musical works); 28 U.S.C. $\$ 1498$ (2000) (patents); 35 U.S.C. $\S 203$ (2000) (patents developed through the use of government research funding under the Bayh-Dole Act); and 42 U.S.C. $§ 2183$ (2000) (atomic energy). The U.S. compulsory license statutes do not contain the restrictions required by Article 31 of TRIPS. See TRIPS Agreement, supra note 66, art. 31. For an authoritative review of United States and Canadian experience with compulsory licensure, see Jerome $\mathrm{H}$. Reichman \& Catherine Hasenzahl, Non-Voluntary Licensing of Patented Inventions: Historical Perspective, Legal Framework under TRIPS, and an Overview of the Practice in Canada and the USA 19-22 (Int'l Ctr. for Trade and Sustainable Dev. \& U.N. Conference on Trade and Dev., Issue Paper No. $5,2003)$.

286. Kades, supra note 44, at 657-59 (discussing, but not resolving, the time-consistency problem).

287. See supra notes 134-14 and accompanying text concerning alternatives to the patent appropriation system. 
future, it could be resolved much more directly today, without bothering with much longer patents.

\section{Longer Patents Constrain Access}

While complaints of complexity and ineffectiveness might dull the charms of Preserving a Precious Resource, a much more serious charge awaits: Pigovian rents will kill people. Low-income patients will be denied important therapies. The demand elasticity for prescription drugs in the U.S. is quite low. In order to change behavior, Pigovian rents on EPK must be quite high. Using prices to ration utilization of EPK will constrain therapeutically important access for the poor. This case is particularly compelling in low-income populations where antibiotic prices are already too high, constraining therapeutically important uses, and thereby encouraging resistance. ${ }^{288}$ A recent economic model predicts widespread treatment failure with the best hope for controlling malaria (FACT therapy) unless multiple FACTs are actively subsidized globally. ${ }^{289}$ Malaria afflicts 300 to 500 million people and kills more than 1 million per year. ${ }^{290}$ Malaria requires Pigovian subsidies, not Pigovian rents, through extended patent terms. ${ }^{291}$

Kades's model tends to equate "maximal production" with "socially optimal," ignoring the questions of distributional equity and access. This is another way of assuming that Pigovian rents will ration for optimal public health. ${ }^{292}$ As discussed in Sections I.A, II.B and III.A.1 above, there is scant evidence for this position in pharmaceutical markets, and considerable experience to the contrary, most notably with equitable access to AIDS drugs. Kades addresses equity concerns by suggesting that government could subsidize antibiotic prices for the poor to ensure access: It is left unsaid whether this principle should be extended globally to the billions who lack affordable access to essential patented drugs. ${ }^{293}$ In any case, these subsidies

288. Byarugaba, supra note 110 , at $618,633-35$. Much longer patents also do not work for the socalled "neglected" diseases which are endemic primarily in the low-income world and therefore do not represent a significant pharmaceutical market. Multiple-drug resistant tuberculosis and malaria are prominent examples.

289. Malaria Resistance, supra note 176, at 9-13.

290. Global Forum for Health Research, supra note 38.

291. Malaria Resistance, supra note 176, at 9-13.

292. Kades, supra note 44, at 665. Brown and Layton make similar assumptions. Brown \& Layton, supra note 54, at 353 ("At any point in time, the central planner can be envisaged as ordering the population from the most sick to the least sick, and treating the most sick first.”).

293. Kades, supra note 44, at 665-67. 
undermine the intended Pigovian effects on these consumers. When these subsidies are added, the last vestiges of a market-based approach are stripped away. Conservation amongst these subsidized populations would require the conservation and education techniques which Kades dismisses as "jawboning." 294

\section{Innovation under Significantly Longer Patents}

The supply-side innovation case for patents is not a major focus of Preserving a Precious Resource, but the issue warrants four comments.

First, longer (or perpetual) patents would indeed strengthen appropriation, but the effect is not linear. Doubling the patent period does not double the net present value (NPV) of R\&D cost recovery. If inflation is at 5\%, the NPV of $\$ 1$ in year 21 is only 35.9 cents. At higher rates of inflation, the NPV drops significantly. ${ }^{295}$ The public domain would be privatized at a discount.

Second, before one embarks upon raising pharmaceutical appropriation rents, consensus should be reached as to whether additional rents are a good idea. Additional pharmaceutical rents come at a great cost to society. Some commentators suggest that pharmaceutical appropriation is already supraoptimal for innovation. ${ }^{296}$ This question must be addressed with transparent and independent research before proceeding.

Third, one must ask what type of innovation is being purchased with appropriation rents. Leaving the debate about incremental ("me-too") innovation to the side, the patent system encourages the production of products that can be sold. Pills for wealthy people fit this category nicely. Knowledge about the optimal conservation characteristics of antibiotics do not. As the prior sections have demonstrated, the biological context will determine, in many cases, the preferred IP and conservation policies for EPK. Kades points out (correctly in my view) that comprehensive information about optimal antibiotic usage is a public good with an optimal price of zero, and thus will not be created in optimal amounts by private actors. ${ }^{297}$ Similarly, we agree that the creation of new vaccines and diagnostic tools for EPK

294. Kades, supra note 44, at 635-38.

295. At a $10 \%$ interest rate, the net present value of a $\$ 1$ payment in year 21 is only 13.5 cents. In one sense, the rate of inflation is a much more important factor than doubling the patent period.

296. See, e.g., Pharmaceutical Arbitrage, supra note 13, at 220-22, and sources cited therein. For conflicting perspectives, see generally supra note 126 .

297. Kades, supra note 44 , at $642-43$. 
conservation serves the public good. ${ }^{298}$ So it seems that the first priority for legal support for R\&D would be these classic public goods, which will be underprovided by the market. Additional pharmaceutical appropriation rents would be better spent on understanding current $\mathrm{EPK}^{299}$ rather than creating anew. ${ }^{300}$ Most importantly, creation of these particular public goods does not require any modification to the patent system, nor do they require Pigovian taxes on consumers. These policy options are quite independent of Kades's main program.

Fourth, any effective program to reduce unnecessary antibiotic use will cut into sales of patented products and, thus, pharmaceutical appropriation. Whether this will largely "undermine" innovation ${ }^{301}$ or is actually an efficiency gain $^{302}$ remains to be proven. Kades assumes a world of patent rights, with innovation through appropriation. But other worlds are possible, including the proposed Global R\&D Treaty, patent buyouts, and innovation prizes. ${ }^{303}$ Freed from the shackles of R\&D cost recovery, drug markets would become truly competitive. Perhaps these options are closer to a free market than what we have today; they certainly would be less susceptible to rentseeking. The question of balancing pharmaceutical access and innovation is open, and the discussion should include options that do not require $R \& D$ cost recovery through consumer prices.

\section{B. Creating New EPK Through Longer Patents}

Several infectious disease experts have recently warned of a global epidemic and the drought of antibiotic innovation. ${ }^{304}$ Prominent examples are

298. Id. at 639-42.

299. In community-acquired pneumonia (CAP), a major disease category for EPK, inadequate clinical information exists on which interventions provide the best cost-benefit. Barlow, supra note 256, at 39, 51. Barlow's review indicates that we do not know whether CAP quality improvement initiatives are costeffective. $I d$. at 51.

300. Similar cases could be made for investments in diagnostics and prophylactics, including Pigovian subsidies for both. Kades supports subsidies for development of diagnostics and prophylactics, but this proposal is in no way tied to the extension of patent terms for EPK. See Kades, supra note 44, at 631, 639-42. Diagnostics are probably not exhaustible resources; prophylactics might be. Again, much longer patents do not provide the needed incentive. For a discussion on the importance of speedy and accurate diagnostics in combating resistance, see Gould, supra note 168, at 710-12.

301. Kades, supra note 44, at 656.

302. Pharmaceutical Arbitrage, supra note 13, at 217-22.

303. See supra notes 138-42 and accompanying text.

304. Richard P. Wenzel, The Antibiotic Pipeline-Challenges, Costs, and Values, 351 New Eng. J. MED. 523-26 (2004); BAD BugS, supra note 1; Projan, supra note 209, at 427-30 (Projan is employed by Wyeth Research). 
the June 2004 report of the Infectious Diseases Society of America (IDSA), BAd Bugs, No Drugs, ${ }^{305}$ and distinguished medical researcher Richard P. Wenzel's recent article in the New England Journal of Medicine. ${ }^{306}$ After authoritative sections on infectious diseases and antibiotic resistance, these reports then wander into patent policy, and generally propose additional pharmaceutical rent appropriation to support $R \& D$. The gloom and doom of Bad Bugs, No Drugs includes some elements of Chicken Little. For the past several years the pharmaceutical industry has highlighted the alleged drought of new antibiotics, ${ }^{307}$ while lobbying Congress to grant additional tax, patent and financial incentives for bioweapons defenses such as antibiotics. ${ }^{308}$ Shortly before the BAD BUGS report went to press, in April 2004, the FDA approved telithromycin (Ketek), the first antibiotic in a powerful new class known as ketolides. ${ }^{309}$ Fourteen months later, in June 2005, a second new antibiotic class was approved, tigecycline (Tygacil), the first drug in the glycylcyclines class. ${ }^{310}$ The same month, June 2005, Pfizer announced the planned purchase of Vicuron Pharmaceuticals Inc., the developer of dalbavancin, a valuable new antibiotic which is expected to be approved by the FDA within a year. ${ }^{311}$ In addition, linezolid became available in 2000 (the first oxazolidinone) and daptomycin became available in 2003 (the first cyclic lipopeptide). ${ }^{312}$ The reports of a "big-pharma" drought of novel antibiotics ${ }^{313}$ appears to have been exaggerated.

Nevertheless, both reports (BAD BUGS and Wenzel) suggest longer patent terms to stimulate antibiotic innovation. Both reports assume, rather than prove, that additional resources need to be directed to the pharmaceutical industry for EPK. ${ }^{314}$ Neither report discusses the negative effect of patents on access to existing therapies ${ }^{315}$ or the relationship between inadequate access and accelerated resistance. ${ }^{316}$ They are silent about the vanishing public

305. BAD Bugs, supra note 1.

306. Wenzel, supra note 304, at 523.

307. Projan, supra note 209, at 427-30; see also Wenzel, supra note 304 ("In 2004, there are few antibacterial agents in the pipeline.").

308. See, e.g., Sarah Lueck, 'Bioshield' Drug-Patent Plan Draws Fire, Wall St. J., Apr. 1, 2005, at $\mathrm{A} 4$ (incentives for anti-bioterrorism drugs).

309. Elliott, supra note 96.

310. See supra note 90 and accompanying text.

311. See supra note 85 and accompanying text.

312. Wenzel, supra note 304 , at 523-26.

313. Projan, supra note 209, at 427-30.

314. See supra Section II.C.1 (critiquing the IP maximalist agenda).

315. See supra Section II.B (discussing the negative externality of access).

316. Intermittent access to medicines can accelerate resistance. Raising prices through enhanced 
domain. Both focus on a single type of innovation-increasing the supply of new drugs - while neglecting conservation R\&D. ${ }^{317}$ None of the issues raised by the intersection of IP law and biological complexity are discussed at all, ${ }^{318}$ even though infectious diseases experts will be essential to understanding these issues.

The aforementioned reports identify a potential weakness in the current pharmaceutical R\&D system, namely, inadequate antibiotic innovation. But the reports assume that the solution is to provide more intellectual property rights. The IDSA and Wenzel are simply espousing the patent agenda of the Pharmaceutical Research and Manufacturers of America (PhRMA), ${ }^{319}$ an organization representing pharmaceutical companies, with virtually no independent analysis.

For example, the IDSA recommends adopting the following expansions of pharmaceutical appropriation: additional tax credits, wildcard patent extensions, longer patent periods, longer orphan drug periods, and reduced FDA standards on safety and efficacy testing. ${ }^{320}$ One would think that in the era of massive drug recalls that reductions in safety and efficacy testing might be seen as dangerous. ${ }^{321}$ The IDSA addresses this exposure by proposing additional liability protections for drug companies. The PhRMA wish list ends with a "guaranteed market." 322 This is the IP maximalist agenda gone wild.

One possible root of this bias can be traced to a joint IDSA/PhRMA/FDA working group meeting in November $2002 .{ }^{323}$ The meeting roster included many speakers sympathetic to PhRMA's desire for greater pharmaceutical appropriation, but apparently no one with a contrary view. ${ }^{324}$ The IDSA never

pharmaceutical appropriation rents may well accelerate resistance. See supra note 110 and accompanying text.

317. See supra Section II.D.

318. See supra Section II.D.6.

319. http://www.phrma.org.

320. BAD BUGS, supra note 1, at 23-26.

321. For a thoughtful (pre-Vioxx) economic analysis of the risks and benefits of faster FDA reviews, see Mary K. Olson, Pharmaceutical Policy Change and the Safety of New Drugs, 45 J.L. \& Econ. 615 (2002).

322. BAD Bugs, supra note 1, at 4.

323. See PhRMA Working Group, supra note 182.

324. For example, Francis P. Tally, M.D. from Cubist Pharmaceuticals, Inc. suggested that the conservation technique of "reserving novel new antimicrobial agents for antimicrobial resistant pathogens" not only "[d]oesn't solve the problem" but also "[r]esults in decreased research in both big pharma and biotech sectors." Francis P. Tally, Drug Development for Resistant Pathogens, PhRMA Working Group, supra note 182 , at 4 . These comments from the most recent developer of novel antibiotic (Cubicin/Daptomycin) illustrate the tension between conservation and innovation, and the temptation to 
heard the other side of the story. The first speaker at the meeting was Richard P. Wenzel.

Wenzel's recent article in the New England Journal of Medicine describes the resistance problem in the conventional fashion, but then assumes that the solution is stronger IP rights. Wenzel supports the supply-side argument with drug industry data ranking the risk-adjusted net present value (NPV) return on investment for various categories of biomedical research. The study concludes that antibiotic research is profitable, but much less profitable than neurologic or musculoskeletal R\&D. Unfortunately, the data for this NPV study was entirely derived from a single drug company and cannot be verified. ${ }^{325}$ Scientists trained in the tradition of double-blind clinical studies should hesitate before embracing data generated exclusively by the interested subjects. Public relations anecdotes from pharmaceutical companies do not constitute reliable data.

Even if these data are accepted, they do not support an extension of patent terms for antibiotics. The problem of disparate returns on investment could be addressed by reducing the patent terms (or pharmaceutical appropriation rents) for drugs with higher financial returns, making antibiotic research more fruitful by comparison. ${ }^{326}$ Alternatively, any market failure in antibiotic R\&D may also be addressed through other coordination mechanisms, such as a Global R\&D Treaty, as discussed in Section II.C above. Increased National Institute of Health (NIH) funding for antibiotic R\&D would be another example. Researchers Croghan and Pittman note that executives in many

waste by a new market entrant. (Tally suggests a conservation strategy of multiple novel drug combinations, which necessitates conservation across classes.) PhRMA's desire for enhanced pharmaceutical appropriation was presented by a senior FDA administrator, Dr. Mark J. Goldberger, now the acting deputy director of CDER. Mark J. Goldberger, Antibiotic Resistance: Incentives for Antimicrobial Development, PhRMA Working Group, supra note 182, at 7 (mentioning "wildcard exclusivity," a form of transferable intellectual property rights where a period of exclusivity is earned on one drug, the antibiotic or orphan drug, but used to garner additional appropriation rents on another drug of the company's choice, such as Lipitor). The speaker from GlaxoSmithKline also noted the tension between conservation and strong market sales. See PhRMA Working Group, supra note 182, at 2-4. Cocchetto was particularly excited by the "high potential impact" (emphasis in original) of wildcard exclusivity. Id. at 6, 17 ("Viable incentives can be achieved via "wild card' market exclusivity and a new [FDA] Guidance.")

325. The source of the NPV data was Wyeth Pharmaceuticals. Projan, supra note 209, at 428 . The underlying data was not disclosed; in fact, the chart is identified as "[a]n example of NPVs" rather than actual data. Id. at 428. Remarkably, this "data" was cited by IDSA as a key finding in BAD BUGS. BAD Bugs, supra note 1, at 3. Wenzel also relied on Projan's NPV table in his article in the New England Journal of Medicine. See Wenzel, supra note 304, at 523-26.

326. If pharmaceutical appropriation rents are already supra-optimal, this reduction would not harm appropriate innovation. See generally Pharmaceutical Arbitrage, supra note 13, at 217-20. 
large pharmaceutical companies began their careers at a time when the triumph over bacteria seemed complete, and thus shunned development of antibiotics. ${ }^{327}$ Supporting graduate programs in infectious diseases and career development grants through the NIH would begin to remedy these issues.

The pharmaceutical companies and their (unwitting) allies in infectious diseases are pushing for expanded IP rights for antibiotics. This Article suggests that many fundamental questions be addressed first, particularly the externalities of waste and access, the priority of EPK conservation, biological complexity and heterogeneity, and the interactions of all of these factors with pharmaceutical appropriation.

\section{CONCLUSION}

Markets create resistance, and resistance creates markets. ${ }^{328}$ When faced with antibiotic resistance, how should society respond? While many are calling for enhanced non-market solutions through enhanced IP law, this Article suggests that we also consider the needs of the poor, as well as those able to afford patented medicines. Society should tailor incentives to the particular type of innovations which are being underprovided by the market. Society also needs to focus on conservation and its complex interactions with biology as well as the patent system and R\&D. Simplistic models may allow drug companies to inappropriately destroy the public domain of exhaustible pharmaceutical knowledge. As important as these arguments are for most health care goods, they are particularly salient for exhaustible pharmaceutical knowledge. Otherwise, the public domain vanishes.

327. Thomas W. Croghan \& Patricia M. Pittman, The Medicine Cabinet: What's In It, Why, And Can We Change The Contents?, 23 Health Aff. 23, 29-30 (2004).

328. See David M. Shlaes, The Abandonment of Antibacterials: Why and Wherefore?, 3 CURRENT Opinions in Pharmacology 470, 472 (2003). 